\title{
Sliding Mode Control of Chaos in a Single Machine Connected to an Infinite Bus Power System
}

\author{
Muthana T. Alrifai $(D)$ and Mohamed Zribi \\ Electrical Engineering Department, College of Engineering and Petroleum, Kuwait University, P.O. Box 5969, 13060 Safat, Kuwait \\ Correspondence should be addressed to Mohamed Zribi; mohamed.zribi10@gmail.com
}

Received 29 March 2017; Revised 18 October 2017; Accepted 7 March 2018; Published 17 April 2018

Academic Editor: Alberto Borboni

Copyright (c) 2018 Muthana T. Alrifai and Mohamed Zribi. This is an open access article distributed under the Creative Commons Attribution License, which permits unrestricted use, distribution, and reproduction in any medium, provided the original work is properly cited.

\begin{abstract}
This paper deals with the control of chaos in a power system. A fourth-order model is adopted for the power system. Three controllers are proposed to suppress the chaos and avoid voltage collapse. The controllers are a feedback linearization controller, a conventional sliding mode controller, and a second-order super-twisting sliding mode controller. It is shown that the proposed controllers guarantee the convergence of the states of the system to their desired values. Simulations studies are presented to show the effectiveness of the proposed control schemes.
\end{abstract}

\section{Introduction}

Electric power systems are generally comprised of threephase AC systems operating essentially at constant voltages. Voltage stability of a power system pertains to the ability of the system to maintain steady acceptable voltages at all buses of the power system under normal operating conditions and also after being subjected to some disturbances. Disturbances can be due to faults on the system, increase in the loads demand, or any other changes affecting the system conditions.

A power system enters a state of voltage instability when a disturbance acting on the system causes a progressive and uncontrollable change in the voltages of the buses. The sequence of events accompanying voltage instability may lead to a low unacceptable voltage profile in a significant part of the power system which in turn may lead to a voltage collapse or a voltage avalanche [1]. It should be mentioned that losses of loads and/or tripping of the transmission lines and the complete shutdown of the affected areas may follow a voltage collapse. In recent years, many parts of countries, such as the USA, Japan, the UK, and France, experienced major blackouts incidents which were associated with voltage collapse.
Moreover, chaos is a nonlinear phenomenon which may affect the stability of some systems. Chaotic oscillations are very sensitive to the parameters and to the initial conditions of the system. They are related to random, continuous, and bounded oscillations. Chaos has been widely investigated in many systems in different areas. Moreover, chaos is categorized as one of the top discoveries of the 20th century, and it is expected that chaos will draw more attention in future studies $[2,3]$.

Several researchers studied the chaotic phenomena in power systems. Early studies were mainly focused on interpreting the behavior of chaotic oscillations of power systems [4-15]. Routes to chaotic oscillations in power systems and relationship between chaos and power system instability were studied in [16-19]. It was reported in [19] that chaos can lead a power system to voltage instability and a voltage collapse when stability conditions are broken. Moreover, it was shown that chaos may possibly exist as an intermediate stage in the instability incident after a large disturbance affecting the power system. In [4], it was shown that voltage collapse phenomenon is linked to static and/or dynamic bifurcation. In addition, it was found that the nominal operating point undergoes dynamic bifurcations prior to the static bifurcation to which voltage collapse was attributed. Some studies 
considered the interaction of chaotic motion and the system dynamic components and the relation between the power system stability region and chaos. Clearly, chaos oscillations in power systems are harmful and should be suppressed or eliminated by using effective control measures. Several control strategies were developed for this purpose.

Since power systems are highly nonlinear, different nonlinear control schemes were used to curb or eliminate the chaotic oscillations in power systems; for example, see [2037]. Global state feedback linearization was applied in [21] to control the chaotic behavior of the power system. Also, adaptive control was used to control chaos of power systems in [22]. Because of their robustness, sliding mode control (SMC) schemes were widely used to control different types of systems [35]. Several types of SMC control schemes were designed to control the chaos and to avoid voltage collapse in power systems; for example, see [27, 28, 36, 37]. However, SMC schemes suffer from the problem of chattering which is undesirable in practice.

Researchers have used many different ways to reduce or eliminate chattering. One solution which is used to reduce chattering is the use of a boundary layer [38]. Inside the boundary layer, the controller is chosen to be a continuous approximation of the switching controller. This solution involves the use of a saturation function to approximate the sign function in the controller. Let $s$ represent the sliding surface. One continuous approximation of the sign function of the sliding surface $\operatorname{sign}(s)$ is defined as follows: $(2 / \pi) \arctan (\mu s)$, where $\mu$ is a positive constant and the approximation error can be decreased by increasing $\mu$ [39]. Other approximation functions of the sign function which were used to alleviate chattering include $s /(|s|+\epsilon)$ and $\tanh (s / \epsilon)$, with $\epsilon$ being a properly chosen scalar. The introduction of a boundary layer eliminates the high-frequency chattering at the price of losing some degree of robustness. Another approach for chattering reduction is through the use of dynamic sliding mode controllers (DSMC) [40]. This is done through placing an integrator (or a strictly proper low pass filter) in front of the system to be controlled [41]. The advantage of this technique is that it does not sacrifice the control accuracy. In addition, high-order sliding mode (HOSM) controllers can also be used to reduce or eliminate the chattering phenomena. For example, researchers such as Bartolini et al. [42, 43], Levant [44], and Shtessel et al. [45] proposed controllers using second-order sliding mode techniques. Many other works dealing with the design of higher order sliding mode controllers and their applications were also presented; for example, see [46-51].

This paper proposes three nonlinear control schemes to suppress chaos and avoid voltage collapse in a power system. The proposed controllers are a feedback linearization controller, a conventional sliding mode controller, and a second-order super twisting sliding mode controller. These control schemes guarantee the convergence of the states of the system to their desired values. Simulations results indicate that the proposed controllers work well in eliminating the chaotic oscillations of the power system and hence preventing voltage collapse.

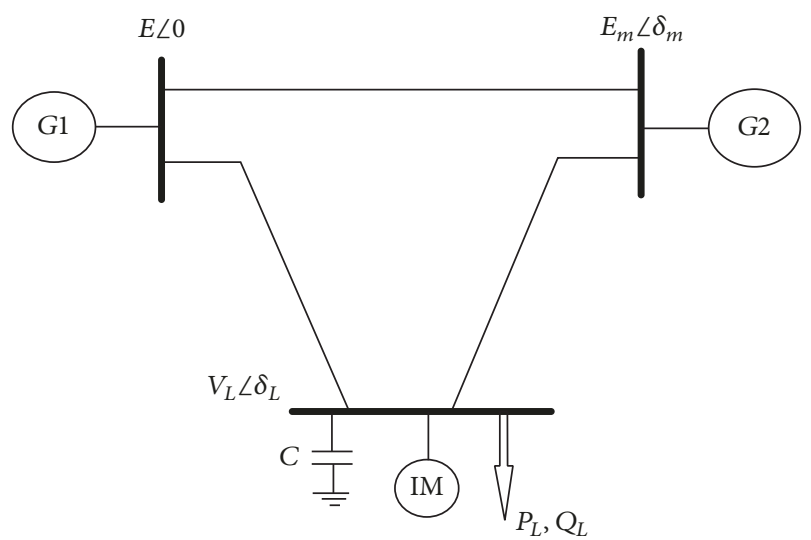

Figure 1: A three-bus power system.

The rest of the paper is organized as follows. The model of a multimachine power system is derived in Section 2. A feedback linearization controller is presented in Section 3. Two sliding mode control schemes are proposed in Sections 4 and 5. Finally, the conclusion is given in Section 6.

\section{Dynamic Model of the Power System}

The power system under consideration consists of a threebus system as shown in Figure 1. In this system, one generator bus is an infinite busbar, while the other one has a constant voltage magnitude $E_{m}$. The Thevenin equivalent model representing the infinite busbar is denoted by $E_{o}$, $Y_{o}$, and $\theta_{o}$. The Thevenin equivalent model representing the second generator is denoted by $E_{m}, Y_{m}$, and $\theta_{m}$. The load bus consists of an induction motor in parallel with a PQ (active, reactive) load. A fixed capacitor is also included with the load to increase the voltage up to near one per unit. The magnitude and phase angle of the load busbar voltage are denoted by $V_{L}$ and $\delta$, respectively.

The motion of the rotor of the generator is given by the swing equation such as

$$
M \ddot{\delta}_{m}+d_{m} \dot{\delta}_{m}=P_{m}-P_{e}
$$

where $\delta_{m}$ is the phase angle of the generator (radians), $M$ is the momentum of inertia of the generator, $d_{m}$ is the damping coefficient, $P_{m}$ is the mechanical power, and $P_{e}$ is the electrical power.

The generator rotor speed deviation $\omega_{m}$ is related to $\delta_{m}$ such that

$$
\dot{\delta}_{m}=\omega_{m}
$$

The generated electrical power $P_{e}$ can be written as

$$
P_{e}=-E_{m}^{2} Y_{m} \sin \left(\theta_{m}\right)-E_{m} V_{L} Y_{m} \sin \left(\delta-\delta_{m}+\theta_{m}\right),
$$

where $Y_{m}$ and $\theta_{m}$ are the magnitude and phase angle of the admittance between the second generator and the load busbar. 
Using (1), (3), and (2), we get

$$
\begin{aligned}
M \dot{\omega}_{m}= & -d_{m} \omega_{m}+P_{m}+E_{m} V_{L} Y_{m} \sin \left(\delta-\delta_{m}-\theta_{m}\right) \\
& +E_{m}^{2} Y_{m} \sin \left(\theta_{m}\right) .
\end{aligned}
$$

The model of the load is as follows [16]:

$$
\begin{aligned}
& P=P_{0}+P_{1}+k_{p w} \dot{\delta}+k_{p v}\left(V_{L}+T \dot{V}_{L}\right) \\
& Q=Q_{0}+Q_{1}+k_{q w} \dot{\delta}+k_{q v} V_{L}+k_{q v 2} V_{L}^{2}
\end{aligned}
$$

where $P_{0}$ and $Q_{0}$ are the constant real and reactive powers of the induction motor, $T$ is the time constant of the motor, and $P_{1}$ and $Q_{1}$ are the real and reactive components of the $P Q$ load. The constants $k_{p w}, k_{p v}, k_{q w}, k_{q v}$, and $k_{q v 2}$ are empirical constants that characterize the load.

The real power supplied to the load bus by the network is expressed as

$$
\begin{aligned}
P= & -E_{0}^{\prime} Y_{0}^{\prime} V_{L} \sin \left(\delta+\theta_{0}^{\prime}\right) \\
& -E_{m} Y_{m} V_{L} \sin \left(\delta-\delta_{m}+\theta_{m}\right) \\
& +\left(Y_{0}^{\prime} \sin \left(\theta_{0}\right)+Y_{m} \sin \left(\theta_{m}\right)\right) V_{L}^{2},
\end{aligned}
$$

where $E_{0}^{\prime}, Y_{0}^{\prime}$, and $\theta_{0}^{\prime}$ are the adjusted values of the Thevenin equivalent model representing the infinite bus in consideration of the capacitor.

The reactive power supplied to the load bus by the network is expressed as

$$
\begin{aligned}
Q= & E_{0}^{\prime} Y_{0}^{\prime} V_{L} \cos \left(\delta+\theta_{0}^{\prime}\right)+E_{m} Y_{m} V_{L} \cos \left(\delta-\delta_{m}+\theta_{m}\right) \\
& -\left(Y_{0}^{\prime} \cos \left(\theta_{0}\right)+Y_{m} \cos \left(\theta_{m}\right)\right) V_{L}^{2} .
\end{aligned}
$$

Using the above equations, we can write

$$
\begin{aligned}
k_{q w} \dot{\delta}=E_{0}^{\prime} Y_{0}^{\prime} V_{L} \cos \left(\delta+\theta_{0}^{\prime}\right)+E_{m} Y_{m} V_{L} \\
\cdot \cos \left(\delta-\delta_{m}+\theta_{m}\right)-k_{q v} V_{L}-Q_{0}-Q_{1}-\left(k_{q v 2}\right. \\
\left.+Y_{0}^{\prime} \cos \left(\theta_{0}^{\prime}\right)+Y_{m} \cos \left(\theta_{m}\right)\right) V_{L}^{2} \\
T k_{q w} k_{p v} \dot{V}_{L}=k_{p w} k_{q v 2} V_{L}^{2}+\left(k_{p w} k_{q v}-k_{q w} k_{p v}\right) V_{L} \\
-k_{q w}\left(E_{0}^{\prime} Y_{0}^{\prime} V_{L} \sin \left(\delta+\theta_{0}^{\prime}\right)\right. \\
\left.+E_{m} Y_{m} V_{L} \sin \left(\delta-\delta_{m}+\theta_{m}\right)\right) \\
+k_{q w}\left(\left(Y_{0}^{\prime} \sin \left(\theta_{0}^{\prime}\right)+Y_{m} \sin \left(\theta_{m}\right)\right) V_{L}^{2}-P_{0}-P_{1}\right) \\
\quad-k_{p w}\left(E_{0}^{\prime} Y_{0}^{\prime} V_{L} \cos \left(\delta+\theta_{0}^{\prime}\right)\right. \\
\left.+E_{m} Y_{m} V_{L} \cos \left(\delta-\delta_{m}+\theta_{m}\right)\right) \\
+k_{p w}\left(\left(Y_{0}^{\prime} \cos \left(\theta_{0}^{\prime}\right)+Y_{m} \cos \left(\theta_{m}\right)\right) V_{L}^{2}+Q_{0}+Q_{1}\right)
\end{aligned}
$$

Collecting (2), (4), (8), and (9), the model of the power system can be represented as follows:

$$
\begin{aligned}
& \dot{\delta}_{m}=\omega_{m}, \\
& M \dot{\omega}_{m}=-d_{m} \omega_{m}+P_{m}+E_{m} V_{L} Y_{m} \sin \left(\delta-\delta_{m}-\theta_{m}\right) \\
& \quad+E_{m}^{2} Y_{m} \sin \left(\theta_{m}\right) \\
& k_{q w} \dot{\delta}=E_{0}^{\prime} Y_{0}^{\prime} V_{L} \cos \left(\delta+\theta_{0}^{\prime}\right)+E_{m} Y_{m} V_{L} \\
& \quad \cdot \cos \left(\delta-\delta_{m}+\theta_{m}\right)-k_{q v} V_{L}-Q_{0}-Q_{1}-\left(k_{q v 2}\right. \\
& \left.\quad+Y_{0}^{\prime} \cos \left(\theta_{0}^{\prime}\right)+Y_{m} \cos \left(\theta_{m}\right)\right) V_{L}^{2}, \\
& T k_{q w} k_{p v} \dot{V}_{L}=k_{p w} k_{q v 2} V_{L}^{2}+\left(k_{p w} k_{q v}-k_{q w} k_{p v}\right) V_{L} \\
& \quad-k_{q w}\left(E_{0}^{\prime} Y_{0}^{\prime} V_{L} \sin \left(\delta+\theta_{0}^{\prime}\right)\right. \\
& \left.\quad+E_{m} Y_{m} V_{L} \sin \left(\delta-\delta_{m}+\theta_{m}\right)\right) \\
& \quad+k_{q w}\left(\left(Y_{0}^{\prime} \sin \left(\theta_{0}^{\prime}\right)+Y_{m} \sin \left(\theta_{m}\right)\right) V_{L}^{2}-P_{0}-P_{1}\right) \\
& \quad+k_{p w}\left(E_{0}^{\prime} Y_{0}^{\prime} V_{L} \cos \left(\delta+\theta_{0}^{\prime}\right)\right. \\
& \left.+E_{m} Y_{m} V_{L} \cos \left(\delta-\delta_{m}+\theta_{m}\right)\right) \\
& \left.\left.+\cos \left(\theta_{0}^{\prime}\right)+Y_{m} \cos \left(\theta_{m}\right)\right) V_{L}^{2}+Q_{0}+Q_{1}\right)
\end{aligned}
$$

We will use the values of the parameters to be the same as in [16]. The parameters of the generator are such that $Y_{m}=$ $5, \theta_{m}=-5, E_{m}=1, P_{m}=1, d_{m}=0.05$, and $M=0.3$. The parameters of the network are such that $Y_{0}=20, \theta_{0}=$ $-5, E_{0}=1, C=12, Y_{0}^{\prime}=8, \theta_{0}^{\prime}=-12$, and $E_{0}^{\prime}=2.5$ The parameters of the load are such that $k_{p w}=0.4, k_{p v}=0.3$, $k_{q w}=-0.03, k_{q v}=-2.8, k_{q v 2}=2.1, T=8.5, P_{0}=0.6$, $Q_{0}=1.3$, and $P_{1}=0.0$. All the parameters values are in per unit except the angles which are in radians.

Therefore, the model of the power system can be written as follows:

$$
\begin{aligned}
\dot{\delta}_{m}= & \omega_{m}, \\
\dot{\omega}_{m}= & p_{1} V_{L} \sin \left(\delta-\delta_{m}+p_{2}\right)+p_{3} \omega_{m}+p_{4}, \\
\dot{\delta}= & p_{5} V_{L} \cos \left(\delta-\delta_{m}-p_{2}\right)+p_{6} V_{L} \cos \left(\delta-p_{7}\right) \\
& +p_{8} V_{L}^{2}+p_{9} V_{L}+p_{10} Q_{1}+p_{11}+u_{1}, \\
\dot{V}_{L}= & p_{12} V_{L} \cos \left(\delta-\delta_{m}-p_{13}\right)+p_{14} V_{L} \cos \left(\delta-p_{15}\right) \\
& +p_{16} V_{L}^{2}+p_{17} V_{L}+p_{18} Q_{1}+p_{19}+u_{2},
\end{aligned}
$$

where the parameters $p_{1}-p_{19}$ in the power system model (11) have the following values: $p_{1}=16.66667, p_{2}=0.087266$, $p_{3}=-0.16667, p_{4}=1.88074, p_{5}=-166.6667, p_{6}=$ -666.66667, $p_{7}=0.20944, p_{8}=496.87181, p_{9}=-93.3333$, $p_{10}=33.33333, p_{11}=43.33333, p_{12}=26.21722, p_{13}=$ 


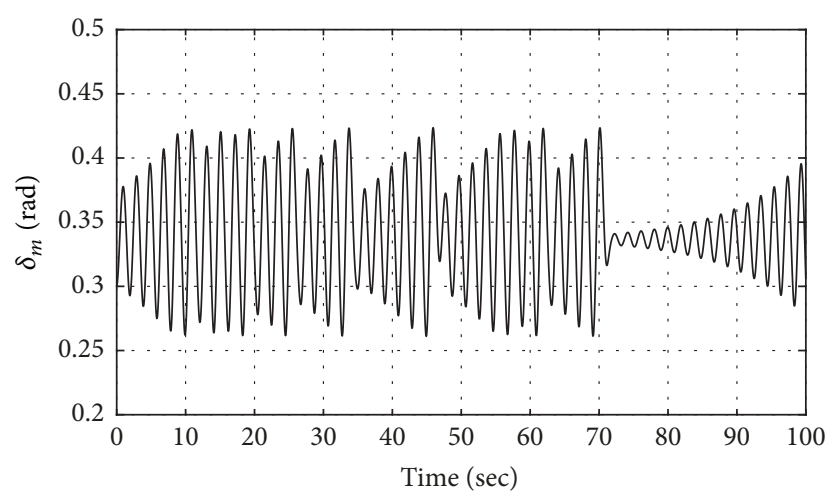

FIGURE 2: The machine power angle $\delta_{m}$ versus time (no control).

0.01241, $p_{14}=104.868887, p_{15}=0.13458, p_{16}=-78.7638$, $p_{17}=14.52288, p_{18}=-5.22876$, and $p_{19}=-7.03268$.

Note that the control inputs for the system in (11) are added to the third and fourth differential equations of the system. Also, recall that $Q_{1}$ is a system parameter representing the reactive power in the system.

For ease of presentation, we define the state variables $x_{1}-x_{4}$ such that $\left[\begin{array}{llll}x_{1} & x_{2} & x_{3} & x_{4}\end{array}\right]^{T}=\left[\begin{array}{llll}\delta_{m} & \omega_{m} & \delta & V_{L}\end{array}\right]^{T}$. Hence, model of the system is expressed as follows:

$$
\begin{aligned}
\dot{x}_{1}= & x_{2}, \\
\dot{x}_{2}= & p_{1} x_{4} \sin \left(x_{3}-x_{1}+p_{2}\right)+p_{3} x_{2}+p_{4}, \\
\dot{x}_{3}= & p_{5} x_{4} \cos \left(x_{3}-x_{1}-p_{2}\right)+p_{6} x_{4} \cos \left(x_{3}-p_{7}\right) \\
& \quad+p_{8} x_{4}^{2}+p_{9} x_{4}+p_{10} Q_{1}+p_{11}+u_{1}, \\
\dot{x}_{4}= & p_{12} x_{4} \cos \left(x_{3}-x_{1}-p_{13}\right)+p_{14} x_{4} \cos \left(x_{3}-p_{15}\right) \\
& +p_{16} x_{4}^{2}+p_{17} x_{4}+p_{18} Q_{1}+p_{19}+u_{2} .
\end{aligned}
$$

The fourth-order model of the power system (12) is simulated when $u_{1}=u_{2}=0$ and with $Q_{1}=11.37$. The simulation results are shown in Figures $2-7$. The machine power angle $\delta_{m}$ versus time and the deviation in the frequency $\omega_{m}$ versus time are shown in Figures 2-3. The load power angle $\delta$ versus time and the load voltage $V_{L}$ versus time are shown in Figures 4-5. The machine power angle $\delta_{m}$ versus the deviation in the frequency $\omega_{m}$ and the machine power angle $\delta_{m}$ versus the deviation in the frequency $\omega_{m}$ and the load voltage $V_{L}$ are presented in Figures 6-7. It is evident from these figures that the power system is chaotic for this value of $Q_{1}$.

The objective of this paper is to design controllers for the power system so that chaos is suppressed.

Let $x_{1 d}, x_{2 d}, x_{3 d}$, and $x_{4 d}$ represent the desired values of $x_{1}, x_{2}, x_{3}$, and $x_{4}$, respectively.

Remark 1. It is clear from the dynamic model of the system given in (12) that the desired (equilibrium) values of the states of the power system satisfy the following two equations:

$$
\begin{aligned}
x_{2 d} & =0 \\
p_{1} x_{4 d} \sin \left(x_{3 d}-x_{1 d}+p_{2}\right)+p_{4} & =0
\end{aligned}
$$

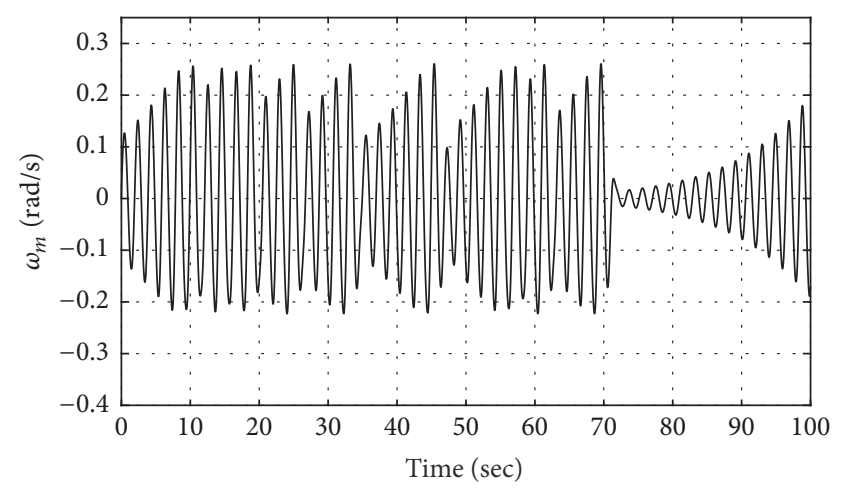

FIgURE 3: The deviation in the frequency $\omega_{m}$ versus time (no control).

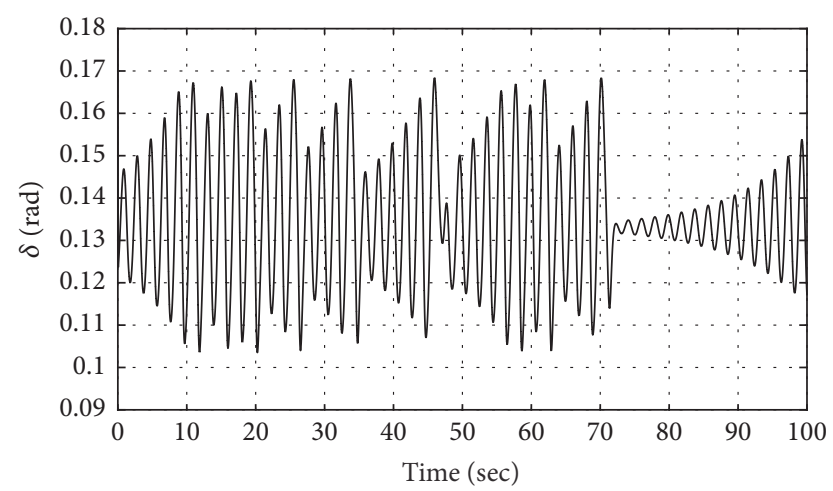

FIgURE 4: The load power angle $\delta$ versus time (no control).

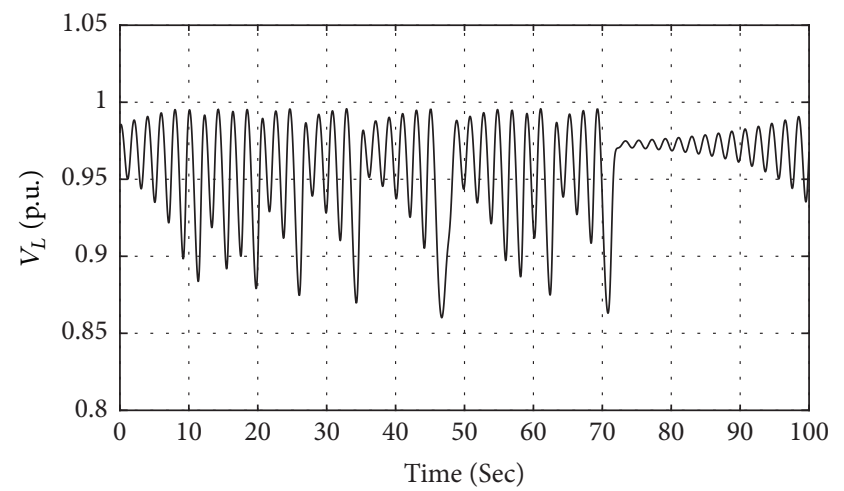

FIgURE 5: The load voltage $V_{L}$ versus time (no control).

To facilitate the design of the controllers, we propose to use the following transformation:

$$
\begin{aligned}
z_{1}= & x_{1}-x_{1 d}, \\
z_{2}= & x_{2}, \\
z_{3}= & p_{1} x_{4} \sin \left(x_{3}-x_{1}+p_{2}\right) \\
& \quad-p_{1} x_{4 d} \sin \left(x_{3 d}-x_{1 d}+p_{2}\right)+p_{3} x_{2}, \\
z_{4}= & x_{3}-x_{3 d} .
\end{aligned}
$$




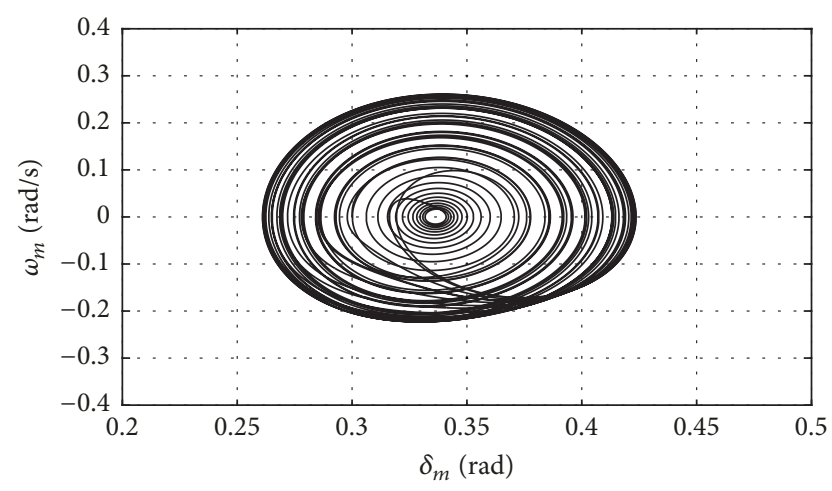

FIGURE 6: The machine power angle $\delta_{m}$ versus the deviation in the frequency $\omega_{m}$ (no control).

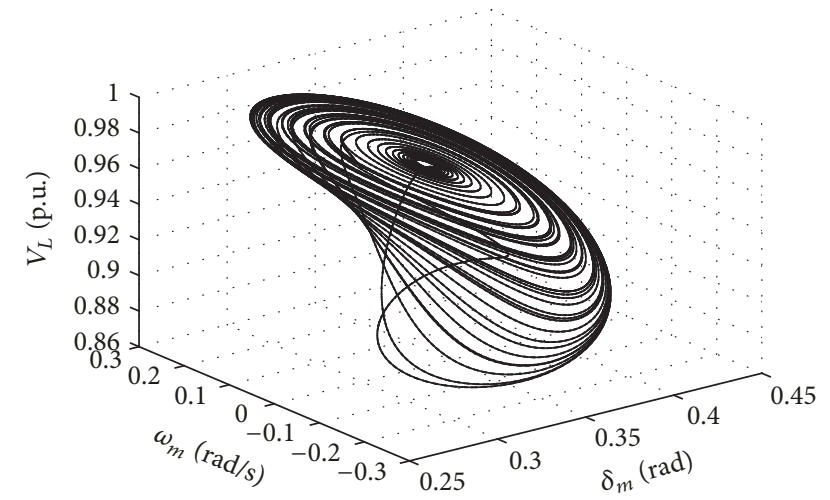

Figure 7: The machine power angle $\delta_{m}$ versus the deviation in the frequency $\omega_{m}$ and the load voltage $V_{L}$ (no control).

Note that $z_{1}(t), z_{2}(t)$, and $z_{4}(t)$ represent the errors between the actual and the desired states for the first three states of the system.

Remark 2. The choice of the states $z_{1}(t), z_{2}(t), z_{3}(t)$, and $z_{4}(t)$ in (14) guarantees that when $z_{1}(t), z_{2}(t), z_{3}(t)$, and $z_{4}(t)$ converge to zero as $t$ tends to infinity, then the states $x_{1}(t), x_{2}(t), x_{3}(t)$, and $x_{4}(t)$ converge to their desired values, respectively.

Using the transformation given in (14), the model of the power system given by the equations in (12) can be written as follows:

$$
\begin{aligned}
& \dot{z}_{1}=z_{2}, \\
& \dot{z}_{2}=z_{3}, \\
& \dot{z}_{3}=f_{1}+\bar{u}_{1}, \\
& \dot{z}_{4}=f_{2}+\bar{u}_{2},
\end{aligned}
$$

where $f_{1}, f_{2}, \bar{u}_{1}$, and $\bar{u}_{2}$ are such that

$$
\begin{aligned}
f_{1} & =p_{1} p_{12} x_{4} \cos \left(x_{3}-x_{1}-p_{13}\right) \sin \left(x_{3}-x_{1}+p_{2}\right) \\
& +p_{1}\left(p_{14} x_{4} \cos \left(x_{3}-p_{15}\right)+p_{16} x_{4}^{2}+p_{17} x_{4}\right.
\end{aligned}
$$

$$
\begin{aligned}
& \left.+p_{18} Q_{1}+p_{19}\right) \sin \left(x_{3}-x_{1}+p_{2}\right)+p_{1} x_{4} \\
& \cdot \cos \left(x_{3}-x_{1}+p_{2}\right)\left(p_{5} x_{4} \cos \left(x_{3}-x_{1}-p_{2}\right)\right. \\
& \left.+p_{6} x_{4} \cos \left(x_{3}-p_{7}\right)+p_{8} x_{4}^{2}\right)+p_{1} x_{4} \\
& \quad \cdot \cos \left(x_{3}-x_{1}+p_{2}\right)\left(p_{9} x_{4}+p_{10} Q_{1}+p_{11}-x_{2}\right) \\
& +p_{3} p_{1} x_{4} \sin \left(x_{3}-x_{1}+p_{2}\right)+p_{3}^{2} x_{2}+p_{3} p_{4}, \\
& f_{2}=p_{5} x_{4} \cos \left(x_{3}-x_{1}-p_{2}\right)+p_{6} x_{4} \cos \left(x_{3}-p_{7}\right) \\
& \quad+p_{8} x_{4}^{2}+p_{9} x_{4}+p_{10} Q_{1}+p_{11}, \\
& \bar{u}_{1}=p_{1} u_{2} \sin \left(x_{3}-x_{1}+p_{2}\right)+p_{1} u_{1} x_{4} \\
& \quad \cdot \cos \left(x_{3}-x_{1}+p_{2}\right) \\
& \bar{u}_{2}=u_{1} .
\end{aligned}
$$

In the following three sections, we will propose three control schemes to suppress chaos in the power system. We will use the transformed model (15) to design the controllers. The controllers will be designed to force the states $z_{1}(t), z_{2}(t)$, $z_{3}(t)$, and $z_{4}(t)$ to converge to zero as $t$ tends to infinity. Hence, the states $x_{1}(t), x_{2}(t), x_{3}(t)$, and $x_{4}(t)$ will converge to their desired values, respectively.

\section{Design of a Feedback Linearization Controller to Suppress Chaos}

3.1. Design of the Controller. Let $\alpha_{1}, \alpha_{2}, \alpha_{3}$, and $\alpha_{4}$ be positive scalars such that the polynomial $P(s)=s^{3}+\alpha_{3} s^{2}+\alpha_{2} s+\alpha_{1}$ is a Hurwitz polynomial.

Theorem 3. The feedback linearization controller

$$
\begin{aligned}
& \bar{u}_{1}=-f_{1}-\alpha_{1} z_{1}-\alpha_{2} z_{2}-\alpha_{3} z_{3} \\
& \bar{u}_{2}=-f_{2}-\alpha_{4} z_{4}
\end{aligned}
$$

when applied to the transformed fourth-order power system given by (15) guarantees the asymptotic convergence of the states $z(t)=\left[\begin{array}{llll}z_{1}(t) & z_{2}(t) & z_{3}(t) & z_{4}(t)\end{array}\right]^{T}$ to zero as $t$ tends to infinity.

Proof. The closed loop system when the control scheme given by (17) is applied to the transformed power system given by (15) can be written as follows:

$$
\dot{z}=A_{t} z
$$

where

$$
A_{t}=\left[\begin{array}{cccc}
0 & 1 & 0 & 0 \\
0 & 0 & 1 & 0 \\
-\alpha_{1} & -\alpha_{2} & -\alpha_{3} & 0 \\
0 & 0 & 0 & -\alpha_{4}
\end{array}\right] .
$$


It can be easily checked that since $\alpha_{1}, \alpha_{2}, \alpha_{3}$, and $\alpha_{4}$ are positive scalars such that $P(s)=s^{3}+\alpha_{3} s^{2}+\alpha_{2} s+\alpha_{1}$ is a Hurwitz polynomial, then the matrix $A_{t}$ is a stable matrix (i.e., its eigenvalues are located in the left half of the complex plane).

The solution of (18) is $z(t)=\exp \left(A_{t} t\right) z(0)$, where $z(0)$ is the initial state at $t=0$. Since $A_{t}$ is a stable matrix, then $z(t)$ will converge to zero as $t \rightarrow \infty$.

Therefore, since $z(t)$ converges to zero as $t \rightarrow \infty$, then the states of the power system will converge to their desired values as $t \rightarrow \infty$ because of the choice of the transformation given by (14).

Remark 4. The design of the controller scheme is accomplished using the transformed dynamic model given by (15). Then the controllers $\bar{u}_{1}$ and $\bar{u}_{2}$ given by (17) are transformed back into the original coordinates such that

$$
\begin{aligned}
& u_{1}=\bar{u}_{2}, \\
& u_{2}=\frac{\left(\bar{u}_{1}-p_{1} \bar{u}_{2} x_{4} \cos \left(x_{3}-x_{1}+p_{2}\right)\right)}{\left(p 1 * \sin \left(x_{3}-x_{1}+p_{2}\right)\right)} .
\end{aligned}
$$

3.2. Simulation Results. The performance of the closed loop system when using the proposed feedback linearization controller was simulated using the MATLAB software. The initial states of the system are such that $\left[\begin{array}{llll}x_{1}(0) & x_{2}(0) & x_{3}(0) & x_{4}(0)\end{array}\right]^{T}=$ [0.3 rad $0 \mathrm{rad} / \mathrm{s} 0.2 \mathrm{rad} 0.97$ p.u. $]^{T}$. The controllers $u_{1}$ and $u_{2}$ given by (17) and (20) are applied to the power system (12). The desired states of the power system are such that $x_{d}=\left[\begin{array}{llll}x_{1 d} & x_{2 d} & x_{3 d} & x_{4 d}\end{array}\right]^{T}=$ $\left[\begin{array}{lll}0.34 \mathrm{rad} & 0 \mathrm{rad} / \mathrm{s} \quad 0.1365 \mathrm{rad} 0.9728 \mathrm{p.u} .\end{array}\right]^{T}$. The simulation results are depicted in Figures 8-11. The machine power angle $\delta_{m}$ versus time and the deviation in the frequency $\omega_{m}$ versus time are shown in Figures 8-9, respectively. The load power angle $\delta$ versus time and the load voltage $V_{L}$ versus time are shown in Figures 10-11, respectively. It is clear from these figures that the states of the power system reach their desired values in less than $3 \mathrm{sec}$. Hence, the proposed feedback linearization controller works well in suppressing chaos in the power system.

It is well known that chaotic systems are very sensitive to initial conditions. Therefore, we simulated the system with the same initial conditions except for $x_{2}(0)=\omega_{m}(0)=$ $0.2 \mathrm{rad} / \mathrm{sec}$. We checked that this initial condition still results in a chaotic system. The simulation results are shown in Figures 12-15. These figures show that the proposed controller still works but the transient responses are not as good as when $x_{2}(0)=\omega_{m}(0)=0 \mathrm{rad} / \mathrm{sec}$.

Feedback linearization controllers are generally not very robust to unmodeled dynamics and external robustness. Therefore, we will use sliding mode controllers in the next two sections to suppress chaos in power systems. Sliding mode controllers will be used because they are well known for their robustness features.

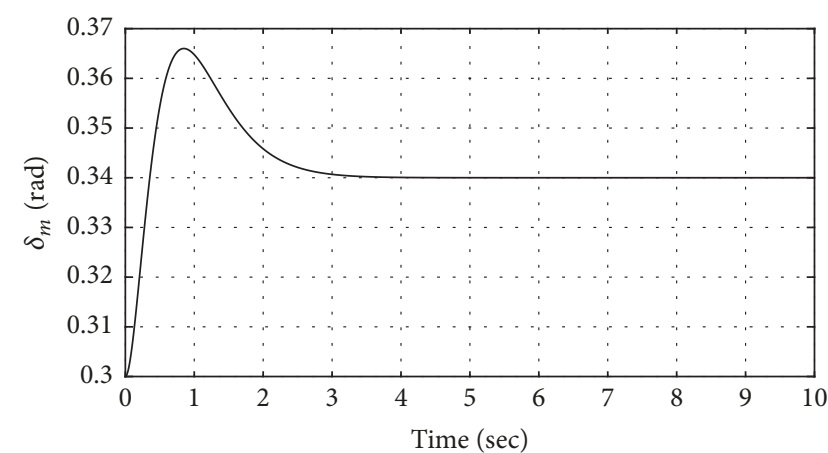

Figure 8: The machine power angle $\delta_{m}$ versus time using the feedback linearization controller when $\omega_{m}(0)=0$.

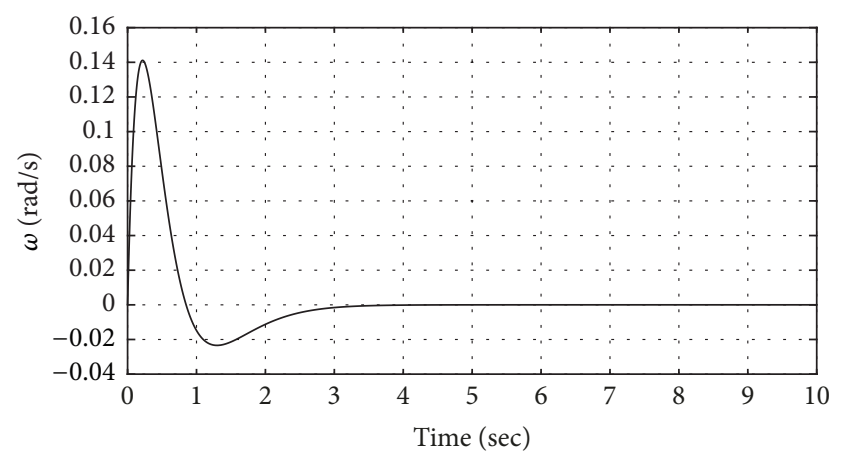

FIGURE 9: The deviation in the frequency $\omega_{m}$ versus time using the feedback linearization controller when $\omega_{m}(0)=0$.

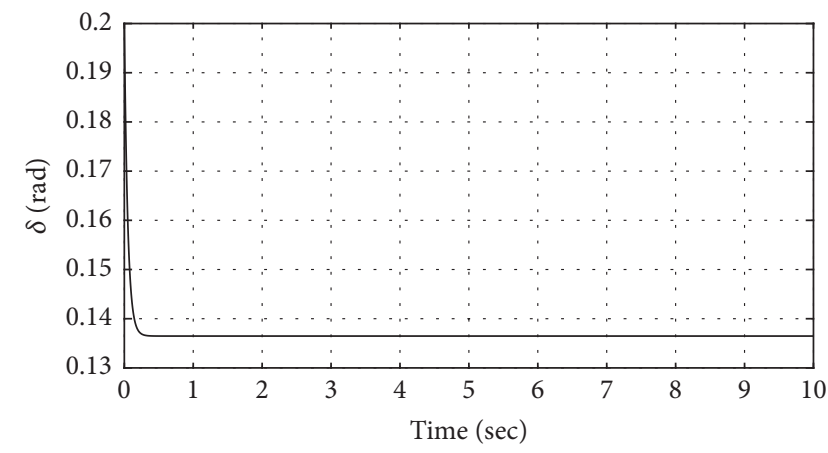

Figure 10: The load power angle $\delta$ versus time using the feedback linearization controller when $\omega_{m}(0)=0$.

\section{Design of a Conventional Sliding Mode Controller to Suppress Chaos}

4.1. Design of the Controller. The first step in the design of sliding mode controllers is the choice of the sliding surfaces. As the power system has two inputs; then two sliding surfaces need to be designed.

Let $\beta_{1}, \beta_{2}, \eta_{1}, \eta_{2}, K_{1}$, and $K_{2}$ be positive scalars. Also, let the sliding surface $S_{1}$ be such that

$$
S_{1}=z_{3}+\beta_{1} z_{1}+\beta_{2} z_{2}
$$




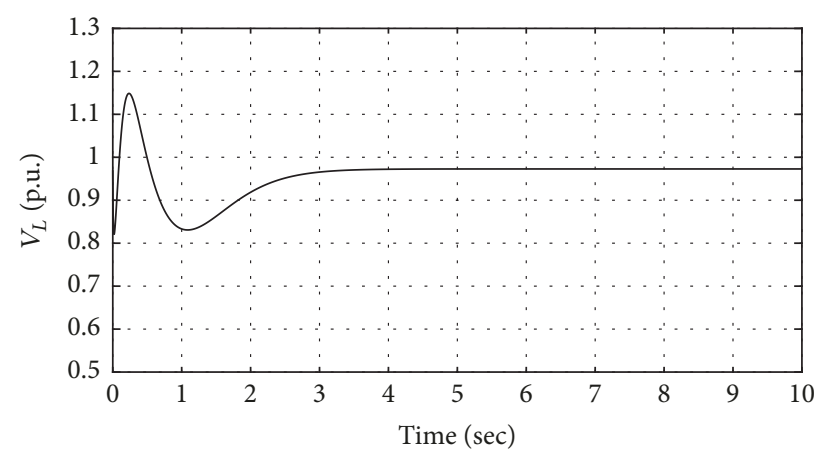

Figure 11: The load voltage $V_{L}$ versus time using the feedback linearization controller when $\omega_{m}(0)=0$.

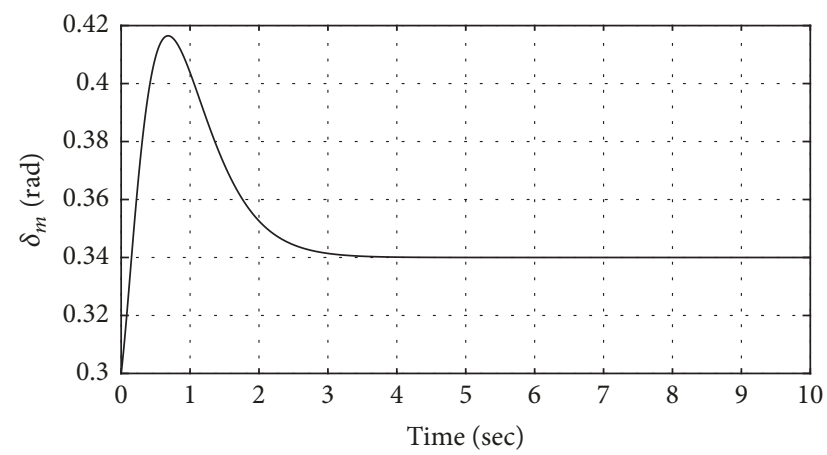

Figure 12: The machine power angle $\delta_{m}$ versus time using the feedback linearization controller when $\omega_{m}(0)=0.2$.

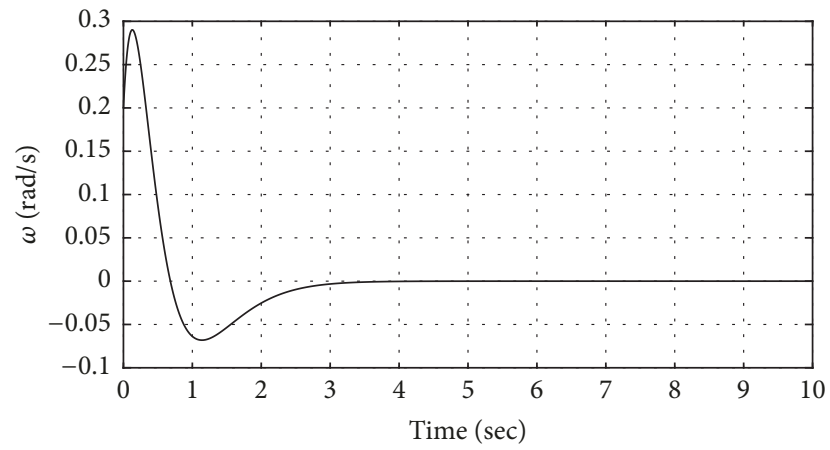

Figure 13: The deviation in the frequency $\omega_{m}$ versus time using the feedback linearization controller when $\omega_{m}(0)=0.2$.

And let the sliding surface $S_{2}$ be such that

$$
S_{2}=z_{4} \text {. }
$$

Theorem 5. The sliding mode controller,

$$
\begin{aligned}
\bar{u}_{1}= & -f_{1}-\beta_{1} z_{2}-\beta_{2} z_{3}-\eta_{1}\left(z_{3}+\beta_{1} z_{1}+\beta_{2} z_{2}\right) \\
& -K_{1} \operatorname{sign}\left(z_{3}+\beta_{1} z_{1}+\beta_{2} z_{2}\right), \\
\bar{u}_{2}= & -f_{2}-\eta_{2} z_{4}-K_{2} \operatorname{sign}\left(z_{4}\right)
\end{aligned}
$$

when applied to the transformed power system model given by (15), ensures that the states $z_{1}(t), z_{2}(t), z_{3}(t)$, and $z_{4}(t)$ converge to zero as tends to infinity.

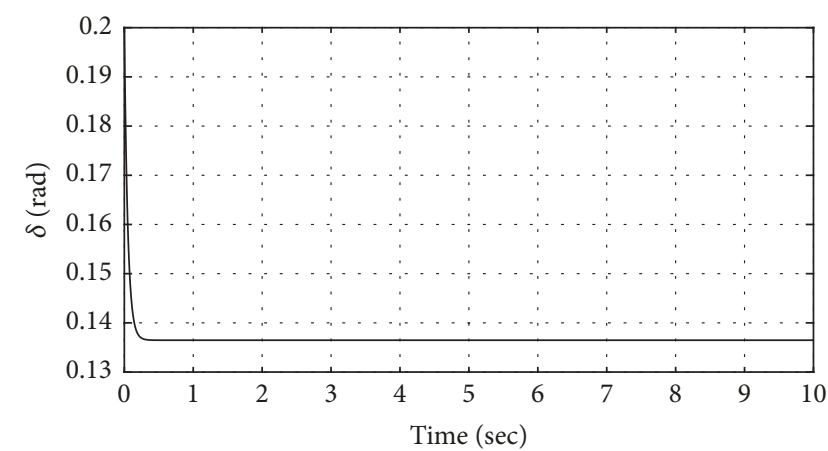

FIgURE 14: The load power angle $\delta$ versus time using the feedback linearization controller when $\omega_{m}(0)=0.2$.

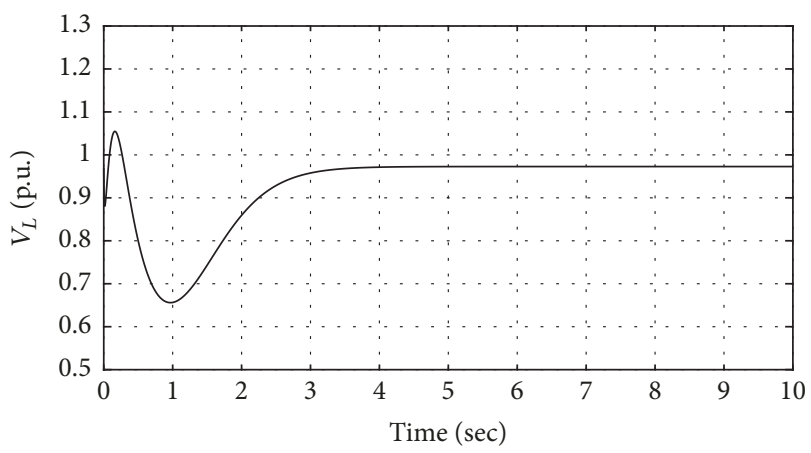

Figure 15: The load voltage $V_{L}$ versus time using the feedback linearization controller when $\omega_{m}(0)=0.2$.

Proof. Differentiating (21) with respect to time and using (15), it follows that

$$
\dot{S}_{1}=\dot{z}_{3}+\beta_{1} \dot{z}_{1}+\beta_{2} \dot{z}_{2}=f_{1}+\bar{u}_{1}+\beta_{1} z_{2}+\beta_{2} z_{3} .
$$

Substituting $\bar{u}_{1}$ by its value from (23), it follows that

$$
\begin{aligned}
\dot{S}_{1}= & f_{1}+\bar{u}_{1}+\beta_{1} z_{2}+\beta_{2} z_{3} \\
= & f_{1}+\beta_{1} z_{2}+\beta_{2} z_{3}-f_{1}-\beta_{1} z_{2}-\beta_{2} z_{3} \\
& -\eta_{1}\left(z_{3}+\beta_{1} z_{1}+\beta_{2} z_{2}\right) \\
& -K_{1} \operatorname{sign}\left(z_{3}+\beta_{1} z_{1}+\beta_{2} z_{2}\right) \\
= & -\eta_{1}\left(z_{3}+\beta_{1} z_{1}+\beta_{2} z_{2}\right) \\
& -K_{1} \operatorname{sign}\left(z_{3}+\beta_{1} z_{1}+\beta_{2} z_{2}\right) \\
= & -\eta_{1} S_{1}-K_{1} \operatorname{sign}\left(S_{1}\right) .
\end{aligned}
$$

Also, differentiating (22) with respect to time, using the model of the transformed system in (15) and substituting $\bar{u}_{2}$ by its value from (24), it follows that

$$
\begin{aligned}
\dot{S}_{2} & =\dot{z}_{4}=f_{2}+\bar{u}_{2}=-\eta_{2} z_{4}-K_{2} \operatorname{sign}\left(z_{4}\right) \\
& =-\eta_{2} S_{2}-K_{2} \operatorname{sign}\left(S_{2}\right) .
\end{aligned}
$$


The dynamic equations (26)-(27) satisfy the following equation:

$$
\begin{array}{r}
S_{i} \dot{S}_{i}=-\eta_{i} S_{i}^{2}-K_{i} S_{i} \operatorname{sign}\left(S_{i}\right)=-\eta_{i} S_{i}^{2}-K_{i}\left|S_{i}\right| \\
\text { for } i=1,2 .
\end{array}
$$

Therefore, the dynamic equations (26)-(27) guarantee that $S_{i} \dot{S}_{i}<0$ for $(i=1,2)$ when $S_{i} \neq 0$. Also, it can be checked that the trajectories associated with the discontinuous dynamics (26) and (27) exhibit a finite time reachability to zero from any given initial condition provided that the scalars $\eta_{1}, \eta_{2}$ are positive and the gains $K_{1}$ and $K_{2}$ are chosen to be large enough strictly positive. Hence, the dynamic equations (26)(27) are guaranteed to reach the surfaces $S_{1}=0$ and $S_{2}=0$ in finite time.

Since $S_{1}$ is driven to zero in finite time, the state variables $z_{1}(t), z_{2}(t)$, and $z_{3}(t)$ are governed after such finite amount of time by the equation $z_{3}+\beta_{1} z_{1}+\beta_{2} z_{2}=0$. Using the transformed model in (15), this equation is equivalent to the second-order differential equation: $\ddot{z}_{1}=-\beta_{2} \dot{z}_{1}-\beta_{1} z_{1}$. The solution of this equation, $z_{1}(t)$, will asymptotically converge to 0 as $t \rightarrow \infty$ because the design parameters $\beta_{1}$ and $\beta_{2}$ are chosen to be positive scalars. In addition, since $z_{1}(t)$ will asymptotically converge to 0 , it can be concluded from the transformed system in (15) that $z_{2}(t)$ will asymptotically converge to 0 as $t \rightarrow \infty$. Similarly, $z_{3}(t)$ will also converge to zero as $t \rightarrow \infty$. In addition, since $S_{2}$ is driven to zero in finite time, the variable $z_{4}(t)$ will converge to zero in finite time.

Therefore, it can be concluded that the sliding mode controller (23)-(24) guarantees the convergence of the state variables $z_{1}(t), z_{2}(t), z_{3}(t)$, and $z_{4}(t)$ to zero as $t \rightarrow \infty$.

Thus, the controller (23)-(24) guarantees the asymptotic convergence of the states of the power system $x_{1}(t), x_{2}(t)$, $x_{3}(t)$, and $x_{4}(t)$ to their desired values as $t \rightarrow \infty$.

Remark 6. To reduce the chattering associated with the proposed sliding mode controller, the switching function sign can be replaced by the saturation function, such that

$$
\operatorname{sat}\left(S_{i}\right)= \begin{cases}\operatorname{sign}\left(S_{i}\right) & \text { if }\left|S_{i}\right|>\epsilon \\ \frac{S_{i}}{\epsilon} & \text { if }\left|S_{i}\right| \leq \epsilon\end{cases}
$$

with $\epsilon$ being a small positive number.

4.2. Simulation Results. The performance of the closed loop system when using the conventional sliding mode controller was simulated using the MATLAB software. The initial and the desired states of the power system are the same as in the previous section. The controllers $u_{1}$ and $u_{2}$ in (20) when $\bar{u}_{1}$ and $\bar{u}_{2}$ are given by (23)-(24) are applied to the power system (12). The simulation results are depicted in Figures 16-19. The machine power angle $\delta_{m}$ versus time and the deviation in the frequency $\omega_{m}$ versus time are shown in Figures 1617 , respectively. The load power angle $\delta$ versus time and the load voltage $V_{L}$ versus time are depicted in Figures 18-19, respectively. These figures indicate that the states of the power system converge to their desired values in less than $3 \mathrm{sec}$.

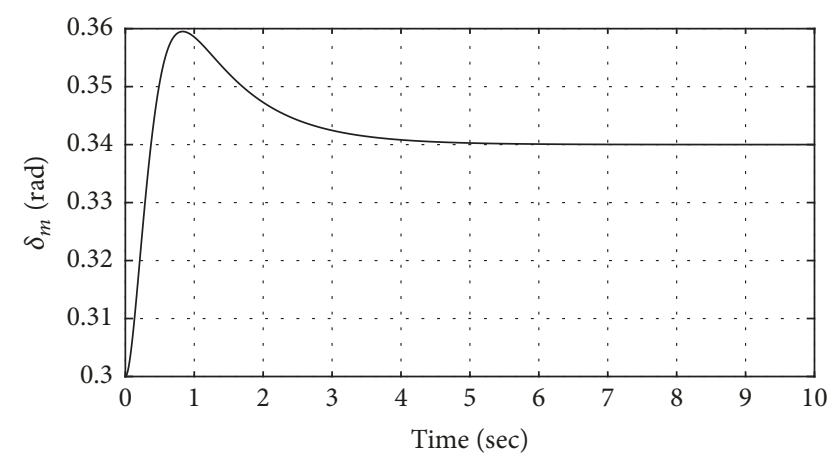

FIgURE 16: The machine power angle $\delta_{m}$ versus time using the conventional sliding mode controller when $\omega_{m}(0)=0$.

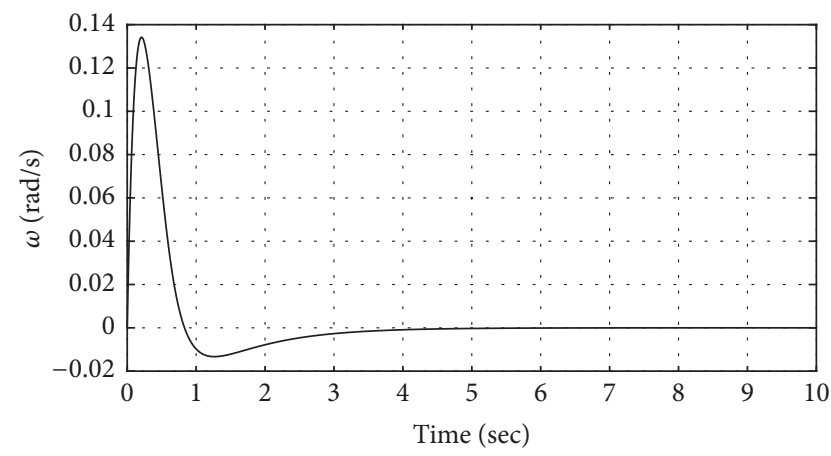

FIGURE 17: The deviation in the frequency $\omega_{m}$ versus time using the conventional sliding mode controller when $\omega_{m}(0)=0$.

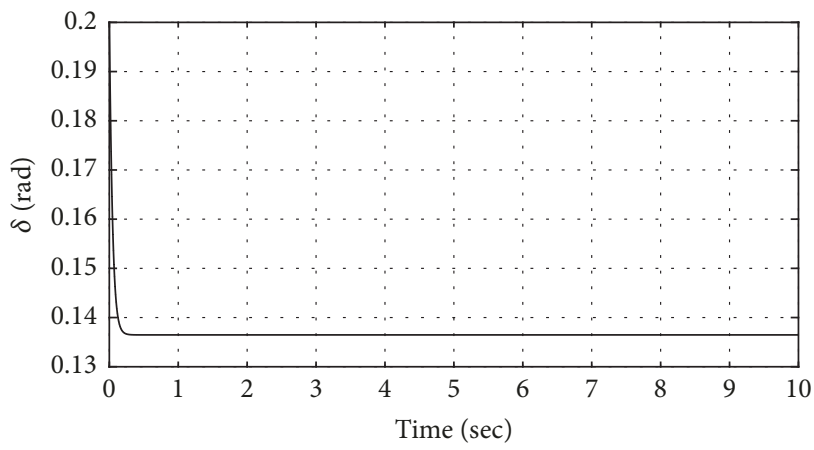

FIGURE 18: The load power angle $\delta$ versus time using the conventional sliding mode controller when $\omega_{m}(0)=0$.

Therefore, it can be concluded that the proposed conventional sliding mode controller works well. Moreover, we simulated the responses of system with the same initial conditions except for $x_{2}(0)=\omega_{m}(0)=0.2 \mathrm{rad} / \mathrm{sec}$. This initial condition still results in a chaotic system. The simulation results are shown in Figures 20-23. Again, these figures show that the proposed controller still work but the transient responses suffer a little bit.

The responses of the states of the system suffer from the well-known chattering problem. Therefore, in the next section, we will use a second-order sliding mode controller [52] to reduce the chattering problem. 


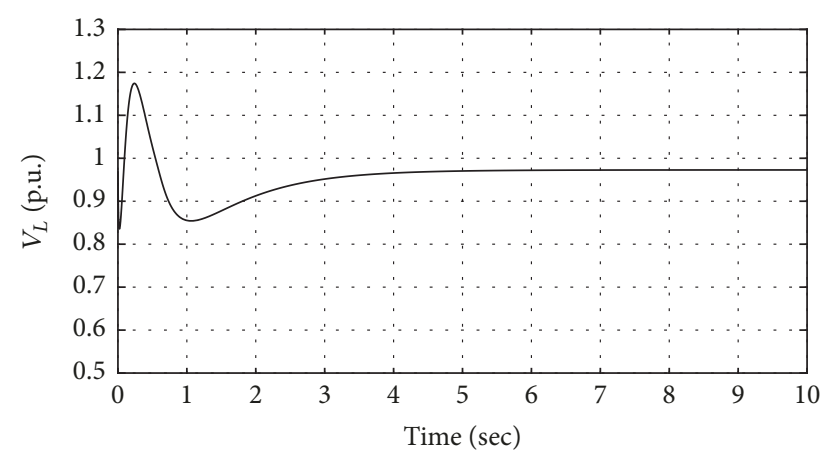

Figure 19: The load voltage $V_{L}$ versus time using the conventional sliding mode controller when $\omega_{m}(0)=0$.

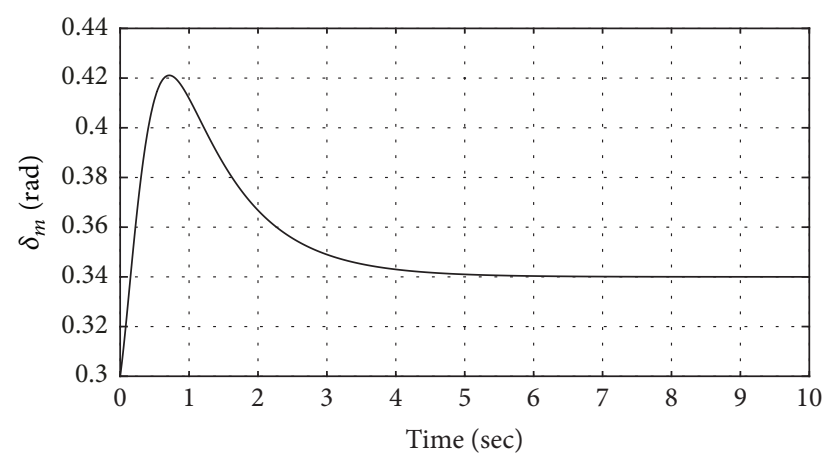

Figure 20: The machine power angle $\delta_{m}$ versus time using the conventional sliding mode controller when $\omega_{m}(0)=0.2$.

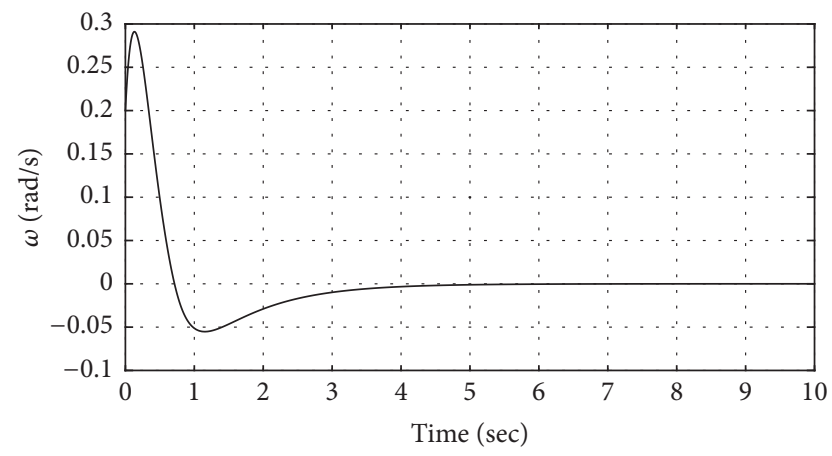

FIgURE 21: The deviation in the frequency $\omega_{m}$ versus time using the conventional sliding mode controller when $\omega_{m}(0)=0.2$.

\section{Design of a Second-Order Sliding Mode Controller to Suppress Chaos}

5.1. Design of the Controller. The controllers given by (23) and (24) suffer from chattering. To remedy this problem, we propose to use the second-order super-twisting sliding mode controller [53]. This controller maintains the robustness features of sliding mode controllers while producing less chattering compared to the conventional sliding mode controller.

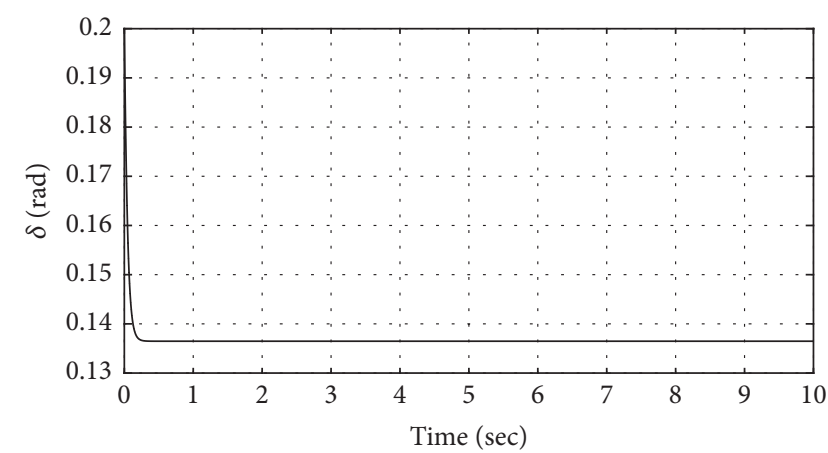

FIgURE 22: The load power angle $\delta$ versus time using the conventional sliding mode controller when $\omega_{m}(0)=0.2$.

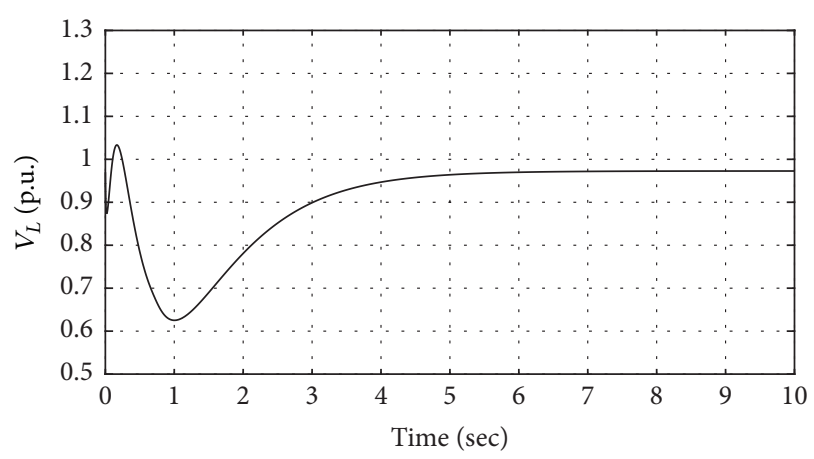

Figure 23: The load voltage $V_{L}$ versus time using the conventional sliding mode controller when $\omega_{m}(0)=0.2$.

We will use the same sliding surfaces as in the previous section, mainly

$$
\begin{aligned}
& S_{1}=z_{3}+\beta_{1} z_{1}+\beta_{2} z_{2}, \\
& S_{2}=z_{4},
\end{aligned}
$$

where $\beta_{1}$ and $\beta_{2}$ are positive scalars. Also, let $\bar{K}_{1}, \bar{K}_{2}, W_{1}$, and $W_{2}$ be positive scalars.

Theorem 7. The second-order sliding mode controller

$$
\begin{aligned}
& \bar{u}_{1}=-f_{1}-\beta_{1} z_{2}-\beta_{2} z_{3}-\bar{K}_{1}\left|S_{1}\right|^{1 / 2} \operatorname{sign}\left(S_{1}\right)+v_{1}, \\
& \bar{u}_{2}=-f_{2}-\bar{K}_{2}\left|S_{2}\right|^{1 / 2} \operatorname{sign}\left(S_{2}\right)+v_{2}
\end{aligned}
$$

with

$$
\begin{aligned}
& \dot{v}_{1}=-W_{1} \operatorname{sign}\left(S_{1}\right), \\
& \dot{v}_{2}=-W_{2} \operatorname{sign}\left(S_{2}\right)
\end{aligned}
$$

when applied to the transformed model of the power system given by (15), ensures that the states $z_{1}(t), z_{2}(t), z_{3}(t)$, and $z_{4}(t)$ converge to zero as t tends to infinity.

Proof. Differentiating the sliding surface $S_{1}$ given by (30) with respect to time and using the transformed model of the power 
system given by (15), and substituting $\bar{u}_{1}$ by its value from (32), it follows that

$$
\begin{aligned}
\dot{S}_{1}= & \dot{z}_{3}+\beta_{1} \dot{z}_{1}+\beta_{2} \dot{z}_{2}=f_{1}+\bar{u}_{1}+\beta_{1} z_{2}+\beta_{2} z_{3} \\
= & f_{1}+\beta_{1} z_{2}+\beta_{2} z_{3}-f_{1}-\beta_{1} z_{2}-\beta_{2} z_{3} \\
& -\bar{K}_{1}\left|S_{1}\right|^{1 / 2} \operatorname{sign}\left(S_{1}\right)+v_{1} \\
= & -\bar{K}_{1}\left|S_{1}\right|^{1 / 2} \operatorname{sign}\left(S_{1}\right)+v_{1} .
\end{aligned}
$$

Also, differentiating the sliding surface $S_{2}$ given by (31) with respect to time, using the transformed model of the power system given by (15), and substituting $\bar{u}_{2}$ by its value from (33), it follows that

$$
\dot{S}_{2}=\dot{z}_{4}=f_{2}+\bar{u}_{2}=-\bar{K}_{2}\left|S_{2}\right|^{1 / 2} \operatorname{sign}\left(S_{2}\right)+v_{2} .
$$

Hence, the dynamics that govern the sliding surfaces $S_{1}$ and $S_{2}$ are as follows:

$$
\begin{aligned}
& \dot{S}_{i}=-\bar{K}_{i}\left|S_{i}\right|^{1 / 2} \operatorname{sign}\left(S_{i}\right)+v_{i}, \\
& \dot{v}_{i}=-W_{i} \operatorname{sign}\left(S_{i}\right)
\end{aligned}
$$

$$
\text { for } i=1,2 \text {. }
$$

The dynamics in (37) correspond to the super-twisting algorithm [54,55]. The finite time convergence to zero of $\left[S_{i}, v_{i}\right]^{T}$ for $(i=1,2)$ was proven in $[54,55]$ by using the Lyapunov function:

$$
V_{i}=\xi_{i}^{T} P_{i} \xi_{i}
$$

where $P_{i}(i=1,2)$ is a positive definite matrix and the vector $\xi_{i}$ is such as $\xi_{i}=\left[\left|S_{i}\right|^{1 / 2} \operatorname{sign}\left(S_{i}\right), v_{i}\right]^{T}(i=1,2)$.

Therefore, the trajectories associated with the discontinuous dynamics (35) and (36) exhibit a finite time reachability to zero from any given initial condition provided that the constants $\bar{K}_{1}, \bar{K}_{2}, W_{1}$, and $W_{2}$ are positive.

Since $S_{1}$ and $S_{2}$ are driven to zero in finite time and following the same arguments as the ones used to prove the previous sliding mode controller, it can be concluded that $z_{1}(t), z_{2}(t), z_{3}(t)$, and $z_{4}(t)$ converge to zero as $t \rightarrow \infty$.

Thus, the controller (32)-(34) guarantees the asymptotic convergence of $x_{1}(t), x_{2}(t), x_{3}(t)$, and $x_{4}(t)$ to their desired values as $t \rightarrow \infty$.

5.2. Simulation Results. The performance of the closed loop system when using the second-order super-twisting sliding mode controller was simulated. The initial and desired states of the power system are the same as in Section 3. The controllers $u_{1}$ and $u_{2}$ given by the relationship (20) and (32)-(34) are applied to the power system (12). The simulation results are depicted in Figures 24-27. The machine power angle $\delta_{m}$ versus time and the deviation in the frequency $\omega_{m}$ versus time are shown in Figures 24-25, respectively. The load power angle $\delta$ versus time and the load voltage $V_{L}$ versus time are shown in Figures 26-27, respectively. These figures

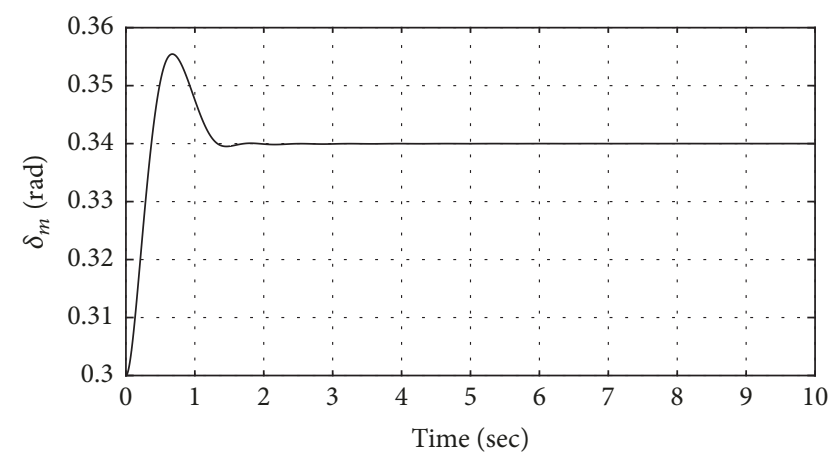

FIgURE 24: The machine power angle $\delta_{m}$ versus time using the second-order sliding mode controller when $\omega_{m}(0)=0$.

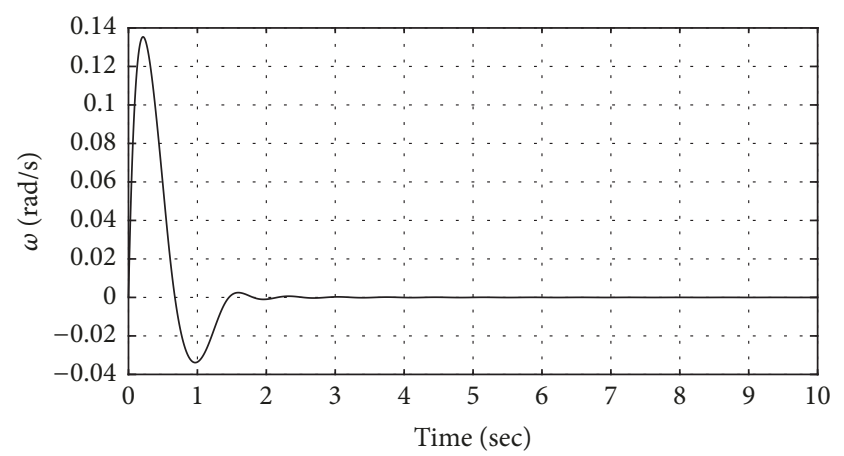

FIgURE 25: The deviation in the frequency $\omega_{m}$ versus time using the second-order sliding mode controller when $\omega_{m}(0)=0$.

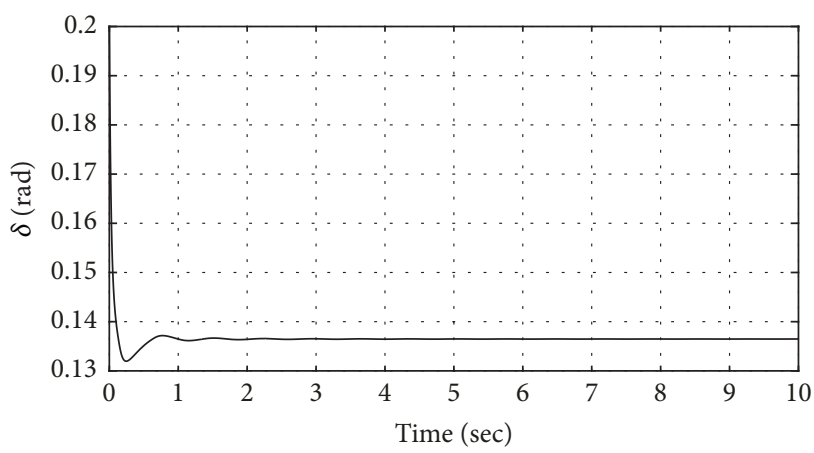

FIGURE 26: The load power angle $\delta$ versus time using the secondorder sliding mode controller when $\omega_{m}(0)=0$.

clearly indicate that the states of the system reached their desired values in less than $2 \mathrm{sec}$. Also, the depicted responses do not suffer from the chattering problem. Hence, it can be concluded that the proposed second-order sliding mode controller works well. Moreover, we simulated the responses of system with the same initial conditions except for $x_{2}(0)=$ $\omega_{m}(0)=0.2 \mathrm{rad} / \mathrm{sec}$. This initial condition still results in a chaotic system. The simulation results are shown in Figures 28-31. Again, these figures show that the proposed controller still work but the transient responses suffer a little bit. 


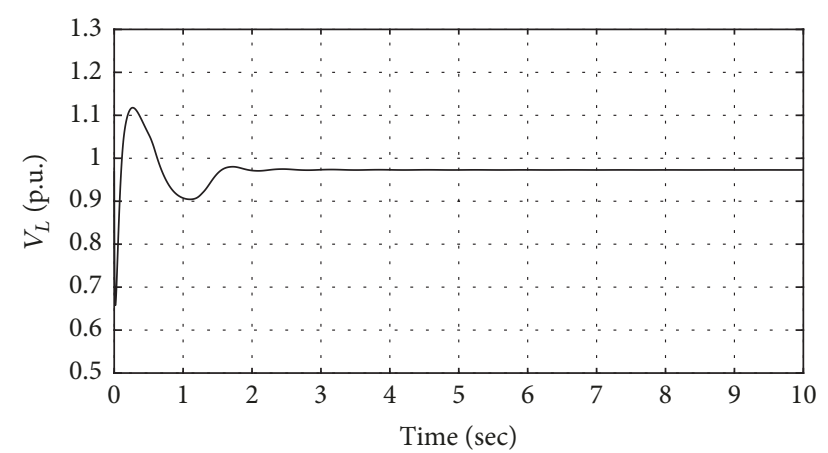

Figure 27: The load voltage $V_{L}$ versus time using the second-order sliding mode controller when $\omega_{m}(0)=0$.

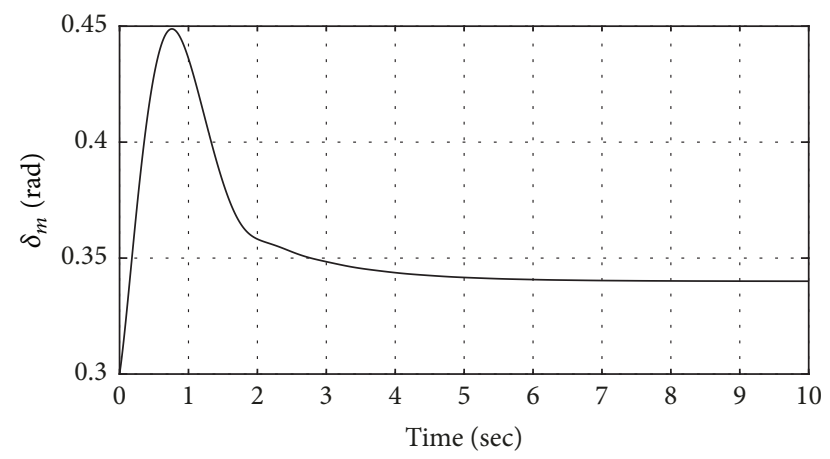

FIgURE 28: The machine power angle $\delta_{m}$ versus time using the second-order sliding mode controller when $\omega_{m}(0)=0.2$.

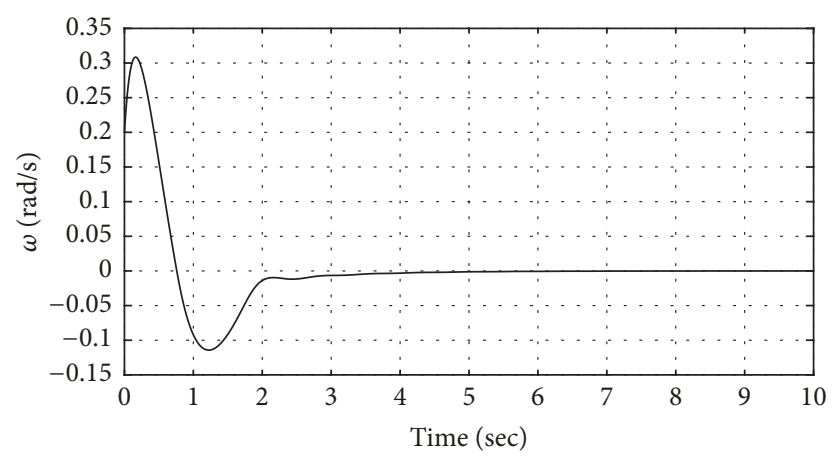

FIgURE 29: The deviation in the frequency $\omega_{m}$ versus time using the second-order sliding mode controller when $\omega_{m}(0)=0.2$.

\section{Conclusion}

The problem of controlling chaos in a power system is studied in this paper. The power system is modeled using four firstorder differential equations. Simulation studies indicate that the system is chaotic for some values of the parameter $Q_{1}$. Three controllers are designed to suppress chaos in the system. The first controller is a feedback linearization controller. The second and third are of the sliding mode type. The simulation results show that the proposed control schemes work well. However, the second-order super-twisting sliding mode controller is the best among the three controllers since

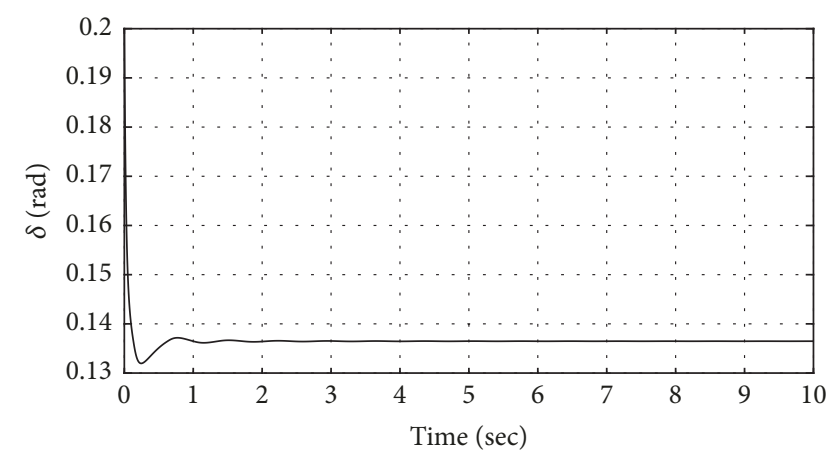

FIgURE 30: The load power angle $\delta$ versus time using the secondorder sliding mode controller when $\omega_{m}(0)=0.2$.

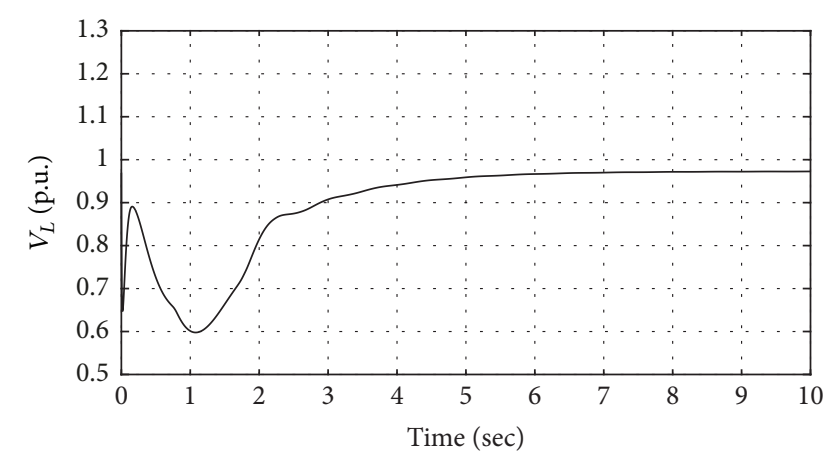

FIGURE 31: The load voltage $V_{L}$ versus time using the second-order sliding mode controller when $\omega_{m}(0)=0.2$.

it possesses robustness features while having the advantage of less chattering as compared to the conventional sliding mode controller.

Future work will address the problem of suppressing chaos using other types of sliding mode control schemes as well as observer based controllers.

\section{Conflicts of Interest}

The authors declare that they have no conflicts of interest.

\section{Acknowledgments}

This research was supported by Kuwait University under Research Grant no. EE03/13.

\section{References}

[1] P. Kundur, Power System Stability and Control, Electric Power Research Institute, McGraw-Hill Inc., New York, NY, USA, 1994.

[2] J. Gleick, Chaos: Making a New Science, Viking Penguin Inc., New York, NY, USA, 12th edition, 1988.

[3] J. Bordogna, “The 21st century engineer," IEEE Spectrum, vol. 38, no. 1, pp. 17-18, 2001.

[4] E. H. Abed and P. P. Varaiya, "Nonlinear oscillations in power systems," International Journal of Electrical Power \& Energy Systems, vol. 6, no. 1, pp. 37-43, 1984. 
[5] V. Ajjarapu and B. Lee, "Bifurcation theory and its application to nonlinear dynamical phenomena in an electrical power system," IEEE Transactions on Power Systems, vol. 7, no. 1, pp. 424-431, 1992.

[6] H.-D. Chiang, C.-W. Liu, P. P. Varaiya, F. F. Wu, and M. G. Lauby, "Chaos in a simple power system," IEEE Transactions on Power Systems, vol. 8, no. 4, pp. 1407-1417, 1993.

[7] H. O. Wang, E. H. Abed, and A. M. A. Hamdan, "Bifurcations, chaos, and crises in voltage collapse of a model power system," IEEE Transactions on Circuits and Systems I: Fundamental Theory and Applications, vol. 41, no. 4, pp. 294-302, 1994.

[8] A. H. Nayfeh, A. M. Harb, and C.-M. Chin, "Bifurcations in a power system model," International Journal of Bifurcation and Chaos, vol. 6, no. 3, pp. 497-512, 1996.

[9] W. Ji and V. Venkatasubramanian, "Hard-limit induced chaos in a fundamental power system model," International Journal of Electrical Power \& Energy Systems, vol. 18, no. 5, pp. 279-295, 1996.

[10] K. G. Rajesh and K. R. Padiyar, "Bifurcation analysis of a three node power system with detailed models," International Journal of Electrical Power \& Energy Systems, vol. 21, no. 5, pp. 375-393, 1999.

[11] Y. X. Yu, H. J. Jia, and C. S. Wang, "Chaotic phenomena and small signal stability region of electrical power systems," Science in China, vol. 44, no. 2, pp. 187-199, 2001.

[12] H. J. Jia, Y. X. Yu, and C. S. Wang, "Chaotic phenomena in power systems and it studies," Proceedings of the CSEE, vol. 21, no. 7, pp. 26-30, 2001.

[13] H. A. Pulgar-Painemal and P. W. Sauer, "Bifurcations and loadability issues in power systems," in Proceedings of the 2009 IEEE Bucharest PowerTech: Innovative Ideas Toward the Electrical Grid of the Future, pp. 1-6, July 2009.

[14] G. Revel, A. E. León, D. M. Alonso, and J. L. Moiola, "Bifurcation analysis on a multimachine power system model," IEEE Transactions on Circuits and Systems I: Regular Papers, vol. 57, no. 4, pp. 937-949, 2010.

[15] D.-Q. Wei, X.-S. Luo, and Y.-H. Qin, "Studying chaos in power system under load perturbation and bounded noise," in Proceedings of the International Conference on Electrical and Control Engineering (ICECE '10), pp. 2185-2188, June 2010.

[16] I. Dobson, H.-D. Chiang, J. S. Thorp, and L. Fekih-Ahmed, "Model of voltage collapse in electric power systems," in Proceedings of the 27th IEEE Conference on Decision and Control, pp. 2104-2109, Austin, Tex, USA, December 1988.

[17] E. H. Abed, H. O. Wang, J. C. Alexander, A. M. Hamdan, and H. Lee, "Dynamic bifurcations in a power system model exhibiting voltage collapse," International Journal of Bifurcation and Chaos, vol. 3, no. 5, pp. 1169-1176, 1993.

[18] Z. Jing, D. Xu, Y. Chang, and L. Chen, "Bifurcations, chaos, and system collapse in a three node power system," International Journal of Electrical Power \& Energy Systems, vol. 25, no. 6, pp. 443-461, 2003.

[19] Y. X. Yu, H. J. Jia, P. Li, and J. F. Su, "Power system instability and chaos," Electric Power Systems Research, vol. 65, no. 3, pp. 187-195, 2003.

[20] H. O. Wang and E. H. Abed, "Bifurcation control of a chaotic system," Automatica, vol. 31, no. 9, pp. 1213-1226, 1995.

[21] A. M. Harb and N. Abdel-Jabbar, "Controlling Hopf bifurcation and chaos in a small power system," Chaos, Solitons \& Fractals, vol. 18, no. 5, pp. 1055-1063, 2003.
[22] D. Q. Wei and X. S. Luo, "Passivity-based adaptive control of chaotic oscillations in power system," Chaos, Solitons \& Fractals, vol. 31, no. 3, pp. 665-671, 2007.

[23] D. Wei, X. Luo, and Y. Qin, "Controlling bifurcation in power system based on LaSalle invariant principle," Nonlinear Dynamics, vol. 63, no. 3, pp. 323-329, 2011.

[24] H. Zhao, Y. Ma, S. Liu, and D. Zhong, "Stabilisation of chaotic power system based on LaSalle invariable principle," International Journal of Automation and Control Engineering, vol. 5, no. 3, pp. 254-266, 2011.

[25] C.-Y. Ma, J.-H. Liu, and C.-L. Wang, "Chaos of a power system model and its control," Journal of Vibration and Control, vol. 18, no. 14, pp. 2176-2185, 2011.

[26] H. Zhao, Y.-J. Ma, S.-J. Liu, S.-G. Gao, and D. Zhong, "Controlling chaos in power system based on finite-time stability theory," Chinese Physics B, vol. 20, no. 12, Article ID 120501, 2011.

[27] Y. Xu, F. Jia, C. Ma, J. Mao, and S. Zhang, "Chatter free sliding mode control of a chaotic coal mine power grid with small energy inputs," International Journal of Mining Science and Technology, vol. 22, no. 4, pp. 477-481, 2012.

[28] Y. Zhang, Z. Zhang, and T. Li, "Adaptive terminal sliding mode control for chaos oscillation of power system," in Electrical, Information Engineering and Mechatronics, pp. 1847-1853, Springer, 2012.

[29] X.-S. Zhou, X.-F. Liu, and Y.-J. Ma, “The study of chaos control in power system," Advanced Materials Research, vol. 413, pp. 7478, 2012.

[30] M. Eslami, H. Shareef, A. Mohamed, and M. Khajehzadeh, "An efficient particle swarm optimization technique with chaotic sequence for optimal tuning and placement of PSS in power systems," International Journal of Electrical Power \& Energy Systems, vol. 43, no. 1, pp. 1467-1478, 2012.

[31] I. M. Ginarsa, A. Soeprijanto, and M. H. Purnomo, "Controlling chaos and voltage collapse using an ANFIS-based composite controller-static var compensator in power systems," International Journal of Electrical Power \& Energy Systems, vol. 46, no. 1, pp. 79-88, 2013.

[32] H. Gholizadeh, A. Hassannia, and A. Azarfar, "Chaos detection and control in a typical power system," Chinese Physics B, vol. 22, no. 1, Article ID 010503, 2013.

[33] X. Zhou, S. Li, and Y. Ma, "Chaos control and its application in power systems," Applied Mechanics and Materials, vol. 316-317, pp. 60-63, 2013.

[34] M. S. Widyan, "Controlling chaos and bifurcations of SMIB power system experiencing SSR phenomenon using SSSC," International Journal of Electrical Power \& Energy Systems, vol. 49, no. 1, pp. 66-75, 2013.

[35] A. Pisano and E. Usai, "Sliding mode control: a survey with applications in math," Mathematics and Computers in Simulation, vol. 81, no. 5, pp. 954-979, 2011.

[36] J. Ni, L. Liu, C. Liu, and X. Hu, "Chattering-free time scale separation sliding mode control design with application to power system chaos suppression," Mathematical Problems in Engineering, vol. 2016, Article ID 5943934, 14 pages, 2016.

[37] J. Ni, L. Liu, C. Liu, X. Hu, and T. Shen, "Fixed-time dynamic surface high-order sliding mode control for chaotic oscillation in power system," Nonlinear Dynamics, vol. 86, no. 1, pp. 401420, 2016.

[38] J. Y. Hung, W. Gao, and J. C. Hung, "Variable structure control: a survey," IEEE Transactions on Industrial Electronics, vol. 40, no. 1, pp. 2-22, 1993. 
[39] R. Xu and Ü. Özgüner, "Sliding mode control of a quadrotor helicopter," in Proceedings of the 45th IEEE Conference on Decision and Control (CDC '06), pp. 4957-4962, December 2006.

[40] H. Sira-Ramirez, "On the dynamical sliding mode control of nonlinear systems," International Journal of Control, vol. 57, no. 5, pp. 1039-1061, 1993.

[41] C. Chen and M. Chen, "A new design for chattering reduction in sliding mode control," IFAC Proceedings Volumes, vol. 41, no. 2, pp. 9877-9881, 2008.

[42] G. Bartolini, A. Ferrara, and E. Usai, "Chattering avoidance by second-order sliding mode control," Institute of Electrical and Electronics Engineers Transactions on Automatic Control, vol. 43, no. 2, pp. 241-246, 1998.

[43] G. Bartolini, A. Ferrara, A. Levant, and E. Usai, "On second order sliding mode controllers," in Variable Structure Systems, Sliding Mode and Nonlinear Control, K. D. Young and U. Zgner, Eds., vol. 247 of Lecture Notes in Control and Information Series, pp. 329-350, Springer-Verlag, London, UK, 1999.

[44] A. Levant, "Principles of 2-sliding mode design," Automatica, vol. 43, no. 4, pp. 576-586, 2007.

[45] Y. B. Shtessel, I. A. Shkolnikov, and M. D. J. Brown, "Asymptotic second-order smooth sliding mode control," Asian Journal of Control, vol. 5, no. 4, pp. 498-504, 2003.

[46] L. Fridman and A. Levant, "Higher order sliding modes," in Sliding Mode Control in Engineering, vol. 11, pp. 53-102, Marcel Dekker, 2002.

[47] A. Levant, "Higher-order sliding modes, differentiation and output-feedback control," International Journal of Control, vol. 76, no. 9-10, pp. 924-941, 2003.

[48] A. Levant, "Quasi-continuous high-order sliding-mode controllers," IEEE Transactions on Automatic Control, vol. 50, no. 11, pp. 1812-1816, 2005.

[49] A. Levant, "Chattering analysis," IEEE Transactions on Automatic Control, vol. 55, no. 6, pp. 1380-1389, 2010.

[50] C. Pukdeboon, A. S. I. Zinober, and M.-W. L. Thein, "Quasi-continuous higher order sliding-mode controllers for spacecraft-attitude-tracking maneuvers," IEEE Transactions on Industrial Electronics, vol. 57, no. 4, pp. 1436-1444, 2010.

[51] Q. Zong, J. Wang, and Y. Tao, "Adaptive high-order dynamic sliding mode control for a flexible air-breathing hypersonic vehicle," International Journal of Robust and Nonlinear Control, vol. 23, no. 15, pp. 1718-1736, 2013.

[52] G. Bartolini, A. Ferrara, E. Usai, and V. I. Utkin, "On multiinput chattering-free second-order sliding mode control," IEEE Transactions on Automatic Control, vol. 45, no. 9, pp. 1711-1717, 2000.

[53] N. Liu, R. Ling, Q. Huang, and Z. Zhu, "Second-order supertwisting sliding mode control for finite-time leader-follower consensus with uncertain nonlinear multiagent systems," Mathematical Problems in Engineering, vol. 2015, Article ID 292437, 8 pages, 2015.

[54] J. A. Moreno and M. Osorio, "Strict Lyapunov functions for the super-twisting algorithm," IEEE Transactions on Automatic Control, vol. 57, no. 4, pp. 1035-1040, 2012.

[55] L. Derafa, A. Benallegue, and L. Fridman, "Super twisting control algorithm for the attitude tracking of a four rotors UAV," Journal of The Franklin Institute, vol. 349, no. 2, pp. 685-699, 2012. 


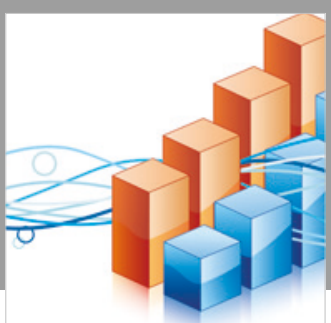

Advances in

Operations Research

\section{-n-m}
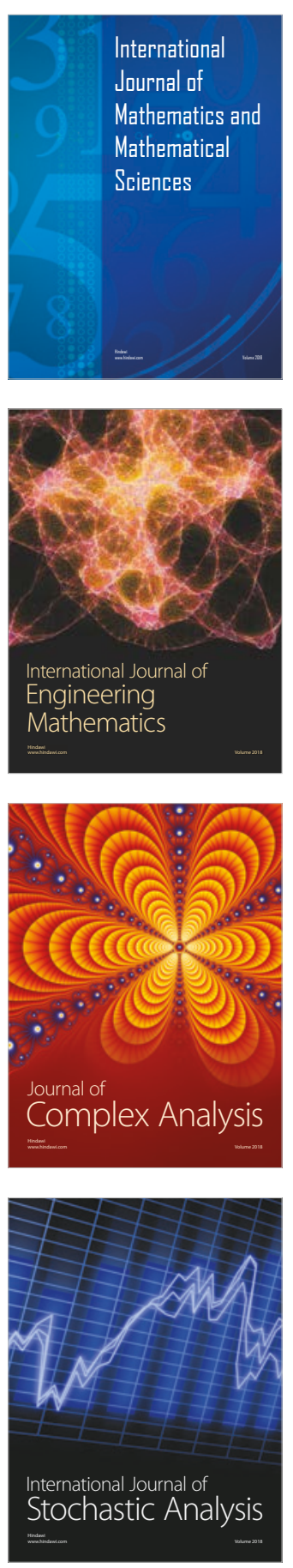
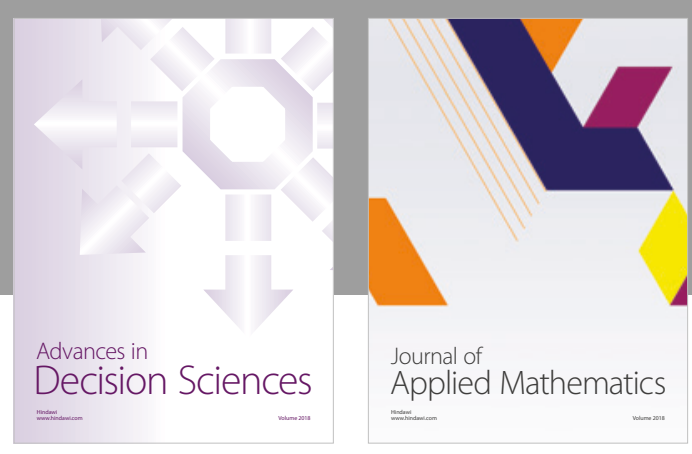

Journal of

Applied Mathematics
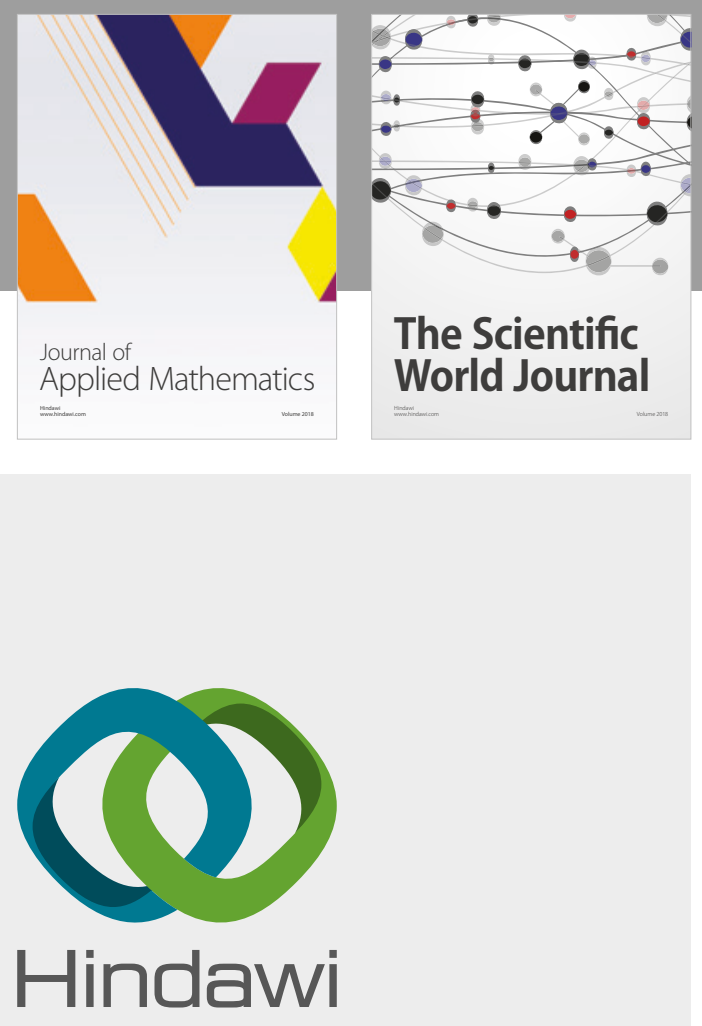

Submit your manuscripts at

www.hindawi.com

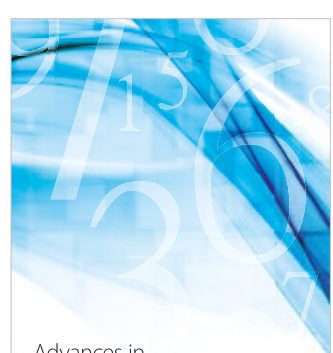

Advances in
Numerical Analysis
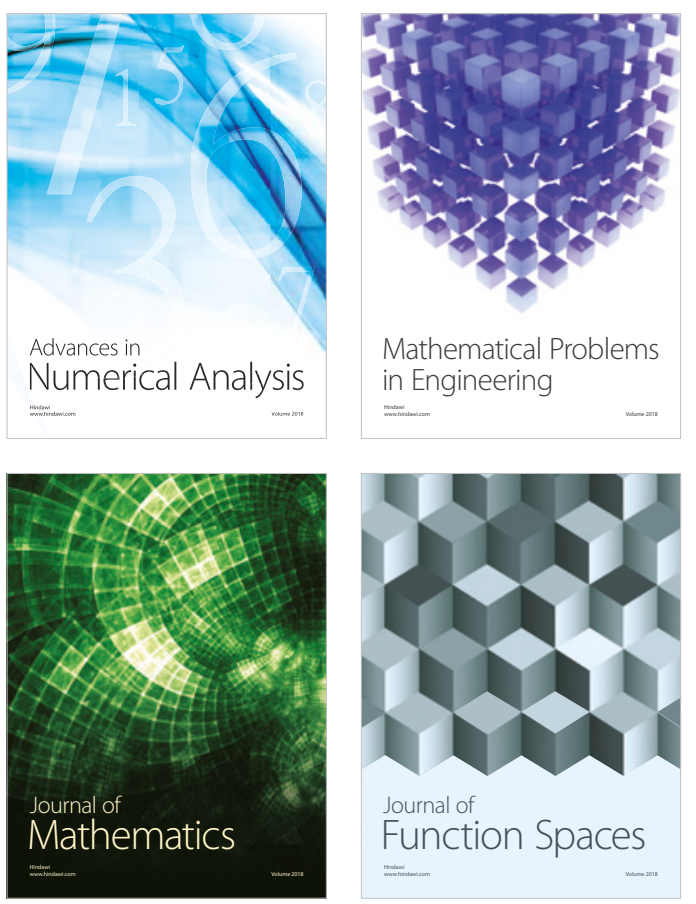

Mathematical Problems in Engineering

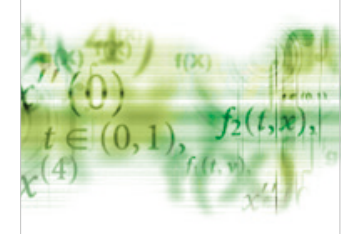

International Journal of

Differential Equations

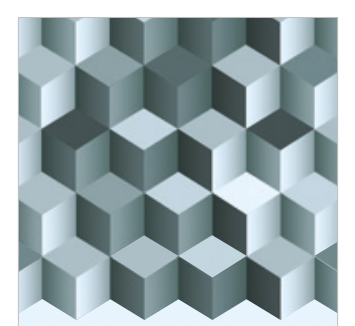

Journal of

Function Spaces

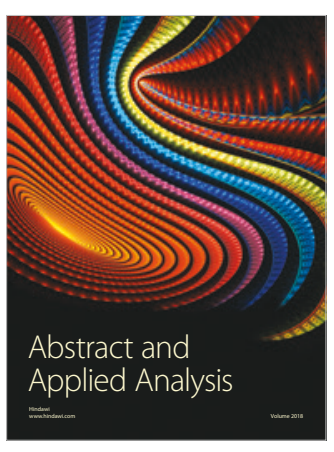

The Scientific

World Journal

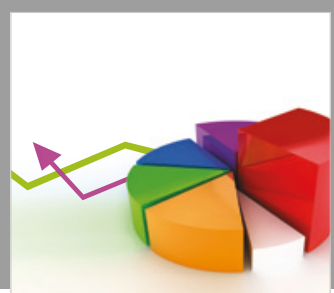

Journal of

Probability and Statistics
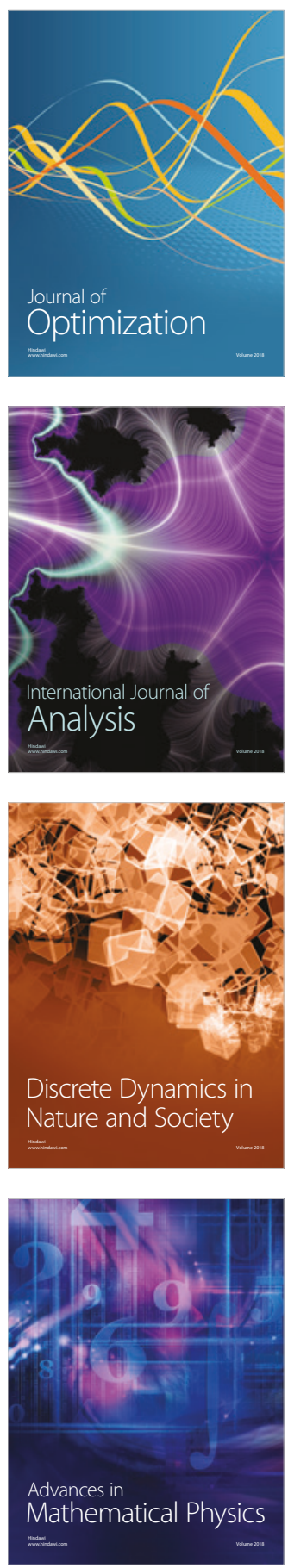